University of Rhode Island

DigitalCommons@URI

Open Access Dissertations

1991

\title{
Correlates of Sibling Jealousy and Parental Favoritism
}

Catherine Gray Deering

University of Rhode Island

Follow this and additional works at: https://digitalcommons.uri.edu/oa_diss

\section{Recommended Citation}

Deering, Catherine Gray, "Correlates of Sibling Jealousy and Parental Favoritism" (1991). Open Access Dissertations. Paper 1031.

https://digitalcommons.uri.edu/oa_diss/1031

This Dissertation is brought to you for free and open access by DigitalCommons@URI. It has been accepted for inclusion in Open Access Dissertations by an authorized administrator of DigitalCommons@URI. For more information, please contact digitalcommons@etal.uri.edu. 
CORRELATES OF SIBLING JEALOUSY AND PARENTAL FAVORITISM BY CATHERINE GRAY DEERING

A DISSERTATION SUBMITTED IN PARTIAL FULLFILLMENT OF THE REQUIREMENTS FOR THE DEGREE OF DOCTOR OF PHILOSOPHY IN CLINICAL PSYCHOLOGY

UNIVERSITY OF RHODE ISLAND 1991 $268 \div 2316$ 


\section{ABSTRACT}

This study explores selected situational, relationship, and personality variables in sibling jealousy among college students $(n=320)$. The research is based on a blend of social psychological and family systems theory, building on recent advances in romantic jealousy research. vignettes portraying sibling and parent-initiated comparison situations were used as a projective technique to elicit sibling jealousy. Results indicate that parent-initiated comparisons produced significantly more jealousy than simple sibling comparisons. Sibling-initiated jealousy was significantly higher in domains of higher relevance or importance to the sample. Comparisons in physical attractiveness, social competence, and athletic achievement produced the highest levels of sibling jealousy. More triangulation, higher intimacy with parents, more conflictual family atmosphere, lower sibling warmth, and coming from a non-intact family predicted higher levels of sibling rivalry and jealousy. Lower personal authority within the family system, higher intergenerational intimidation, more triangulation, lower sibling warmth, more positive family atmosphere, having same sex siblings, and being higher in the birth order predicted higher levels of sibling conflict. Investigation of differences among participants identifying themselves as favorites, non-favorites, and neutrals in their own families revealed that favorites had significantly higher levels of self-esteem than non-favorites. Non-favorites had 
significantly lower levels of personal authority within the family system than favorites and neutrals. The results are discussed with implications for further research and practice. 
The author wishes to thank the following people for their help:

Allan Berman, for his consistent support, encouragement, wisdom, and guidance during this project and throughout my graduate education.

Lisa Harlow, for her undying enthusiasm, commitment to excellence, generous availability, and strong role modeling as a teacher and as a person.

Gweneth Rae, for her insightful comments, balanced perspective, and esprit de corps.

Dominic Valentino, Yvonne Wells, Jennifer Fernald, and Michael Surrette, for their generous help in recruiting participants.

Students from the University of Rhode Island for their eager participation in the study.

Nadine Kaslow, for her encouragement, inspiration, and friendship.

The author's parents, William and Anne Gray; and sisters, Patty Redline, Nancy Peck-Gray, and Mary Beth Gray, for their love and lifelong support.

Thomas Deering for his patience, flexiblity, and loving partnership throughout the graduate school experience. 
TABLE OF CONTENTS

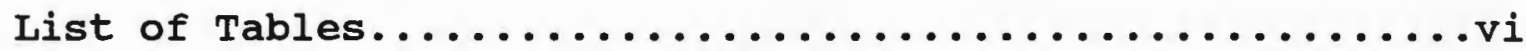

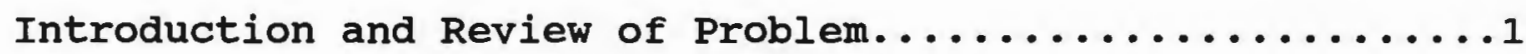

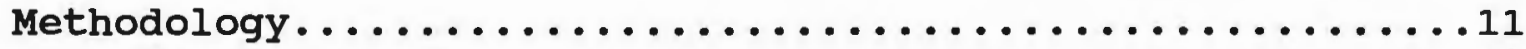

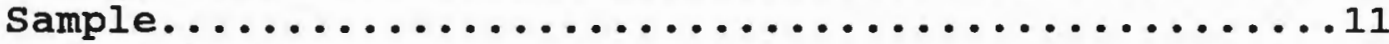

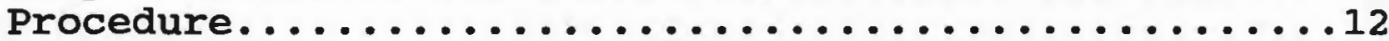

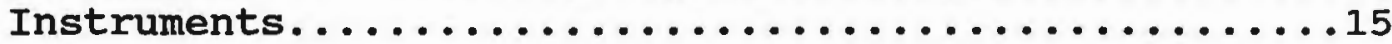

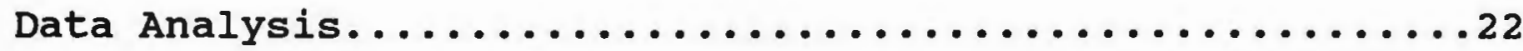

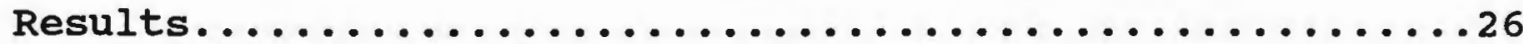

Sibling Versus Parent-Intiated Comparisons........26

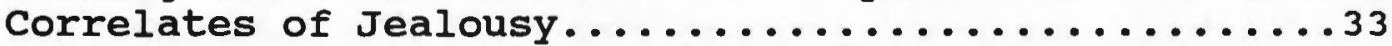

Personal Authority within the Family system and

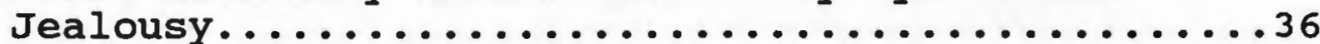

Family Constellation Variables and Jealousy........43

Favoritism.............................46

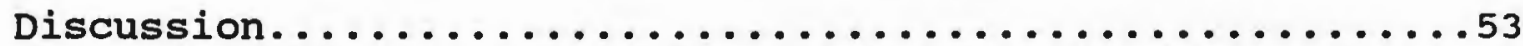

Situational and Relationship Factors in Sibling

Jealousy.............................. 54

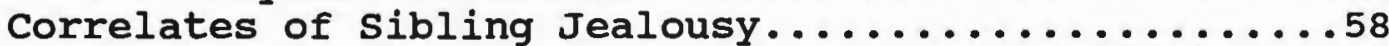

Personal Authority in the Family system and Sibling

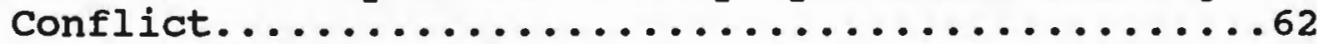

Personal Authority within the Family system and

Sibling Jealousy.......................64

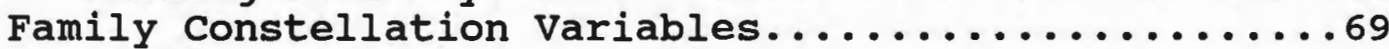

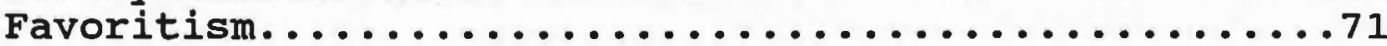

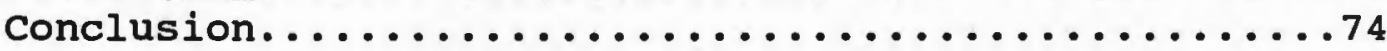

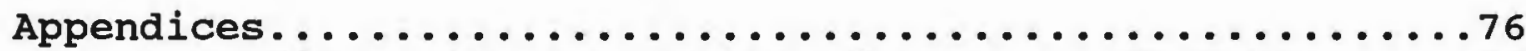

Appendix A: Sibling-Initiated Jealousy Vignettes....76

Appendix B: Parent-Initiated Jealousy Vignettes.....77

Appendix C: Response Format: Sibling-Initiated

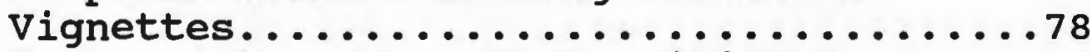

Appendix D: Response Format: Parent-Initiated

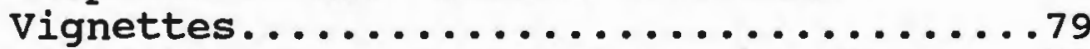

Appendix E: Items for Assessing Jealousy Domains....8 80

Appendix F: Rosenberg Self-Esteem Scale...........82

Appendix G: Family Atomsphere Questionnaire........84

Appendix H: Favoritism status Questions...........85

Appendix I: Informed Consent Form..............87

Appendix J: Demographic and Family Information

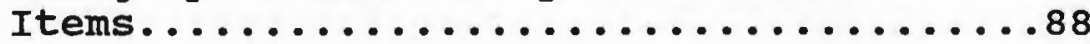

Bibliography ...............................90 
Table 1: Demographic Characteristics of Sample........13

Table 2: Family Characteristics of Sample............14

Table 3: one Factor PCA on Jealousy Items...........24

Table 4: Within Subjects Repeated Measures T-Test on Mean Jealousy Scores for Sibling Vs. Parent-

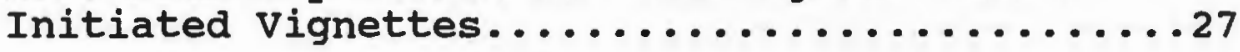

Table 5: Mean Jealousy Scores By Type of Vignette.....29

Table 6: Mean Ratings on Importance of Jealousy Domains.30

Table 7: Within Subjects T-Test on Mean Jealousy Scores for High and Low Importance Sibling-Initiated

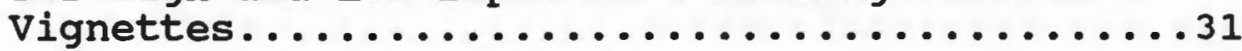

Table 8: Within Subjects T-Test on Mean Jealousy Scores for High and Low Importance Parent-Initiated

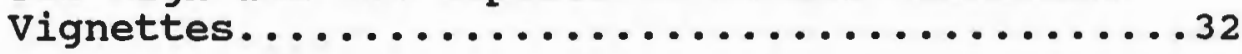

Table 9: Standard Multiple Regression of Selected Variables on sibling Rivalry................ 34

Table 10: Standard Multiple Regression of selected Variables on Sibling conflict..................

Table 11: Standard Multiple Regression of PAFS-Q Subscales on Jealousy.....................

Table 12: Standard Multiple Regression of PAFS-Q Subscales on Sibling-Initiated Jealousy......38

Table 13: Standard Multiple Regression of PAFS-Q Subscales on Parent-Initiated Jealousy.......40

Table 14: Standard Multiple Regression of PAFS-Q Subscales on sibling Rivalry ...........41

Table 15: Standard Multiple Regression of PAFS-Q Subscales on sibling Conflict...........42

Table 16: Standard Multiple Regression of Family Constellation Variables on Sibling Rivalry....44

Table 17: Standard Multiple Regression of Family Constellation Variables on Sibling Conflict....46 
Table 18: Favoritism status of Subjects.............44

Table 19: Favoritism Questionnaire Responses..........45

Table 20: One Way ANOVA of Self-Esteem By Favoritism

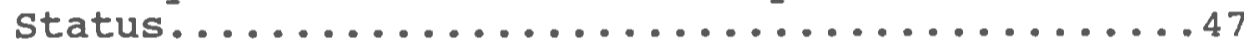

Table 21: One Way ANOVA of Total PAFS-Q Scores By Favoritism status...................48

Table 22: Newman Keuls Test of Mean PAFS-Q Scores By Favoritism status..................48 
Correlates of Sibling Jealousy and Parental Favoritism

Over the past ten years there have been great advances in research on romantic jealousy. Sibling jealousy and parental favoritism have not been as well studied, perhaps because of difficulties with the research process in this area. Social taboos against admissions of sibling jealousy and favoritism pose a problem for self-report measures. Marital jealousy researchers note that they often have to avoid using the word "jealous" in their measures because of social desirability problems (Bringle \& Buunk, 1985). Since sibling jealousy has more immature, perjorative connotations than marital jealousy, there may be even greater social desirability concerns, especially for adults. Romantic jealousy is considered relatively natural and commonplace. Several researchers who have tried to measure sibling jealousy and parental favoritism have encountered difficulty developing measures that are reliable and valid (Daniels \& Plomin, 1985; Furman \& Buhrmester, 1985). Direct psychometric measures of the phenomenon seem to be unstable and have little predictive value thus far. At the same time, clinical papers and case studies with both clinical and nonclinical populations suggest that sibling jealousy and favoritism are prevalent throughout the lifespan (Bank, 1989; Bank, 1987; McHale, Sloan, \& Simeonsson, 1986; Harris \& Howard, 1984; Cicerelli,1982; Ross \& Milgram, 1982; Adams, 1968; Koch, 1956). Given the wealth of case material on 
sibling rivalry and favoritism, there is a surprising lack of research on this phenomenon.

The purpose of this study was to explore specific situational, individual, and relationship variables potentially associated with sibling jealousy. The study was designed to test a theoretical model and to extend the model to situations involving parental favoritism. The research was based on White \& Mullen's (1989) definition of jealousy as a complex of thoughts, emotions, and actions resulting when there is a threat to self-esteem or to a relationship (in this case, the parent-child relationship). The proposed study distinguished between two forms of sibling jealousy identified by Ross \& Milgram (1982), I) sibling- initiated jealousy, which is based on the siblings' own comparisons and, 2) parent-initiated jealousy, which is based on parental comparisons and results in preference or favoritism. Other studies have tended to merge sibling rivalry with parental favoritism (Furman \& Buhrmester, 1985). This study asserts the importance of clarifying the relationship between the two, with the premise that parental favoritism activates, heightens, and maintains jealousy between siblings. The theoretical framework is based on a blend of social psychology and family systems theory.

First, the study explored situational variables related to sibling jealousy and parental favoritism. The hypothesis was that parent-initiated comparisons create more 
jealousy than sibling-initiated comparisons. Jealousy invoked by parent-initiated comparisons was expected to be more global and less domain-specific than simple sibling comparisons, because parental comparisons would increase the relevance or importance of the domain in the eyes of the sibling. Next, the study explored how a number of individual and relationship variables would correlate with sibling jealousy. Higher levels of separation/individuation, less dependence on parental approval, higher self-esteem, less closeness in sibling age, intactness of family structure, greater sibling warmth/closeness, and more positive family atmosphere were expected to predict lower levels of sibling jealousy.

Situational Factors and Sibling Jealousy

situational influences on sibling jealousy may be viewed from the perspective of Tesser's self-evaluation maintenance model (SEM model) (Tesser, 1980; Tesser \& Campbell, 1980; Tesser \& Collins, 1988; Tesser, Millar, \& Moore, 1988). This is a motivational model based on the idea that people strive to maintain positive selfevaluations. Threats to self-evaluation or promises of gains in self-evaluation are emotionally arousing (Tesser \& Campbell, 1980). According to the model, much of social behavior is influenced by two antagonistic processes: 1) the reflection process, which can lead to more positive 
self-evaluations because it involves basking in the reflected glory of a close other (Cialdini, Thorne, Walker, Freeman, \& Sloan, 1976), and 2) the comparison process, which can lead to more negative self-evaluations because it involves seeing the positive performance of another and believing that one's own performance pales in comparison. A limitation of the SEM model is that it does not account for cases in which "basking in reflection" may lead to decreased self-esteem (e.g., feeling ashamed of an alcoholic sibling), and cases in which comparison processes lead to increased self-esteem (e.g., feeling superior to a low-achieving sibling). This limitation, however, is not a problem for studies of jealousy since these types of reflections and comparisons are not involved in jealous reactions. In jealousy situations, comparisons with rivals threaten selfesteem. However, self-esteem is not threatened and jealousy is minimized when one can bask in the reflected glory of someone who excels in a unique area that does not diminish one's own accomplishments.

According to the SEM model, two variables which can affect the comparison process are 1) the closeness of the other and, 2) the relevance of the other's performance. Tesser (1980) found that the closer siblings are in age, the more likely they will say they are different. Tesser theorizes that when siblings outperform each other, the less successful siblings try to reduce the relevance of the task 
by defining themselves differently. This is consistent with the studies of sibling deidentification that describe how siblings strive to develop different identities in order to preserve self-esteem and reduce conflict (Schacter, 1985; Schacter, Shore, Feldman-Rotman, Marquis, \& Campbell, 1976). According to Tesser (1980), the self-evaluation maintenance model suggests that family members who develop separate career pursuits will enjoy basking in the reflected glory of each other, but family members who pursue similar interests will make comparisons which threaten self-esteem and strain their relationships. Tesser's studies suggest that the comparison process induces both more "sibling friction" and poorer father-son relationships when there are occupational similarities across relationships (Tesser, 1980).

Several recent studies have applied the SEM model to non-family jealousy situations, confirming the notion that people are more jealous along domains of higher relevance to them and in situations where social comparison processes are induced (Salovey \& Rodin, 1984; Bers and Rodin, 1984). High relevance situations are defined as performances in a dimension that is highly self-defining for the person (e.g., the same career or interest area) (Tesser, 1980).

The present study investigated sibling jealousy by further testing and extending the SEM model in various situations. It began by testing the hypothesis that sibling jealousy is greater in domains of higher relevance. To 
extend the model, the study compared sibling-initiated jealousy to parent-initiated jealousy. The premise was that parent-initiated comparisons would heighten jealousy by making the self-evaluation process more salient, especially when parents acted on their comparisons by showing favoritism. Ross and Milgram (1982) concluded from their qualitative study of rivalry and favoritism among adult siblings that, "Comparisons, whether made by others or self, were not merely descriptive but evaluative- they translated quantitative statements into value judgements. Simply having more or less success does not generate sibling rivalry. When more becomes better, rivalry ensues. 'Better' may be defined by the standards of a significant other or those internalized by the self." This study asserts that the parental value judgement whereby "more becomes better" automatically increases the relevance of a particular domain for the sibling's self-definition. Therefore, parent-initiated comparisons were expected to create jealousy which is more pronounced, more global, and less domain-specific. This would be particularly true for siblings who have stronger attachments to parents and who value parental opinions. 
Individual and Relationship Correlates of Sibling Jealousy

In addition to situational factors, the literature on romantic jealousy has identified a number of important individual and relationship variables, such as self-esteem and intimacy, which have yet to be investigated with regard to sibling jealousy. A second purpose of this study was to identify how some of these variables may operate in cases of sibling jealousy, and to explore relationships with other, possibly unique variables.

For example, just as romantic jealousy has been shown to correlate with lower levels of self-esteem (Bringle, 1981; Jaremko \& Lindsey, 1979), sibling jealousy would be expected to show correlations with this variable, especially if one defines jealousy as a threat to self-esteem.

Greater dependence on the relationship has proven to be an important correlate of romantic jealousy (Bringle \& Gray, 1986; Amstutz, 1982; White, 1981; White, 1980). Likewise, greater dependence on parental intimacy and approval, lower levels of separation/individuation, and less wellestablished peer relationships would seem to predict higher levels of sibling jealousy in young adults.

Individuals with more well-defined personal goals, who are able to differentiate their own expectations from those of their parents would seem to be less prone to sibling jealousy and less reactive to parental favoritism. The small amount of research on developmental aspects of jealousy 
supports these hypotheses. For example, Bers and Rodin's (1977) investigation of the developmental course of social comparison jealousy found that whereas younger children tended to be more globally jealous of any child's successes, older children were only jealous in well-defined areas that were important to them. The researchers attributed this to the older children's higher levels of identity development. Harris \& Howard (1984) also found that perceived favoritism toward siblings of adolescents was correlated with the feeling of "not knowing who or what I am". Developmental aspects of sibling jealousy in young adults were explored further in this study.

other unique variables explored included parental intimacy, triangulation (overly close relationship and coalition with one parent against the other), family atmosphere (level of harmony versus conflict), and sibling intimacy. Tesser's (1980) early studies explored sibling closeness only in terms of age ranges and inferred family conflict through reviews of biographies of famous men. The relationships between jealousy, sibling intimacy, and other unique variables need more systematic investigation.

Family constellation variables such as birth order, family size, sex of siblings, and intactness of family may influence levels of sibling jealousy. Some studies found significant relationships between these variables and sibling rivalry (Hoopes \& Harper, 1987; Stotland, Sherman, \& 
Shaver, 1971; Toman, 1976) but the findings have been inconsistent. Several studies have found no significant. correlations between birth order, family size, and jealousy (Bers \& Rodin, 1984; Bringle \& Williams, 1979). Robey, Cohen \& Epstein (1988) recently found that children from divorced families were more sensitive to parental affection shown toward other siblings than children from intact families. Further exploration of family constellation variables may help to clarify these inconsistent findings. Finally, the study further investigated the favoritism component of sibling jealousy by examining correlates of favoritism status. This part of the study focused on respondents who identified themselves as favorites, nonfavorites, or "neutrals" (i.e., no favoritism shown) in their families. It was expected that those who perceive themselves as favorites would have higher self-esteem than non-favorites. At the same time, the perceived occurrence of favoritism in families would seem to create more conflict and concern about parental rejection or approval (Bank, 1989; Ross \& Milgram, 1982). For this reason, both favorites and non-favorites were expected to have more trouble separating form their families in a healthy way than those who see themselves as unaffected by favoritism. In summary, the overall design and selection of variables for this study stems from literature review, clinical experience, and hypotheses regarding how sibling 
jealousy may differ from other forms of jealousy. It was influenced by the contention of jealousy researchers that the most thorough and balanced research in this area takes into account person, situation, and relationship variables (Bringle \& Bunk, 1985). The design of this study included variables from all three of these areas.

This research was based on the assumption that sibling jealousy and parental favoritism are natural, inevitable reactions undeserving of their pejorative connotations. As researchers of romantic jealousy note, jealous reactions may be a healthy sign when they signal caring and concern for a valued relationship (Bringle \& Buunk, 1986). It is unreasonable to expect that siblings will never envy each other since envy is a universal emotion (Schoeck, 1966). It is unrealistic to expect that parents will feel and behave exactly the same way toward children who have different personalities and behaviors. By studying sibling jealousy, we may be able to understand what variables contribute to more problematic cases of sibling jealousy and favoritism. In the process, we may reduce the taboo against discussing these problems and discover patterns that have important implications for clinical work with children and families.

In summary, the three main purposes of this study were to 1) test and extend the SEM model as applied to sibling jealousy, 2) to investigate possible correlates of sibling 
jealousy, and 3) to examine aspects of favoritism. The hypotheses of the study were as follows:

1) Jealousy evoked by parent-initiated comparisons would be greater than jealousy produced by simple sibling comparisons.

2) Jealousy evoked by parent-initiated comparisons would be more global and less domain-specific than jealousy generated by simple sibling comparisons.

3) Lower levels of sibling jealousy would be associated with higher levels of separation-individuation, higher selfesteem, more positive family atmosphere, less closeness in sibling age, and intactness of family structure.

4) Individuals who identified themselves as favorites would have higher self-esteem than those who identified themselves as non-favorites.

5) Individuals who identified themselves as either favorites or non-favorites would have lower levels of personal authority within the family system than individuals who perceived no favoritism in their families.

\section{Methodology}

Sample

The sample consisted of 320 undergraduate students from introductory psychology courses. Of these, 67\% $(n=216)$ were females and $32 \%(n=101)$ were males. Ninety percent $(n=288)$ 
of participants 1 isted their race as white, $4 \%(n=13)$ hispanic, $2 \%(n=6)$ black, $1 \%(n=5)$ oriental, and $1 \%(n=3)$ other racial group. Demographic data for the sample are detailed in Table 1.

Interestingly, the most well-represented sibling position in the sample was the youngest child. Forty percent $(n=130)$ were youngest children, $33 \%(n=105)$ oldest children, $20 \%(\mathrm{n}=64)$ middle children, and $5 \%(\mathrm{n}=17)$ only children. The average number of years between participants and their closest sibling was 2.9 , with a range of 0 to 9 years, and a median of 2.0 years. Family size ranged from 0 to 8 or more siblings, with an average of 2.9 children per family. Seventy percent $(n=225)$ of participants indicated that they grew up in intact families with both of their natural parents. Family data for the sample are detailed in Table 2 .

\section{Procedure}

Participants were recruited from several large introductory psychology classes. Some classes required a minimum level of research participation and gave credit for involvement in this study. Other classes gave students extra credit for participating. Instructors told the students that the study involved filling out questionnaires about "family relationships". In order to prevent possible 
Table 1

Demographic Characteristics of Sample

Variable

Gender

Male

Female

Age

$\begin{array}{cr}18 & 3 \\ 19 & 12 \\ 20 & 9 \\ 21 & 41 \\ 22 & 1 \\ 23-26 & 18 \\ 27-30 & 4 \\ 31-36 & 5\end{array}$

Years Educ.

Freshman

Sophomore

Juntor

Sentor

Graduate

Race

White

Black

Hispanic

Oriental

Am. Indian

Other

Father's Educ.

Post-grad.

College Grad.

Beyond H.S.

High School

Grade School

Mother's Educ.

Post-grad.

College Grad.

Bejond H.S.

High School

Grade School
Value Frequenct

$1 \quad 101$

216

67.5

.9

40.0

29.7

12.8

5.9

5.6

1.2

1.5
$49.1 \quad 13.73 \quad .91$

29.1

11.2

6.3

3.7

$90.0 \quad .194 \quad .71$

1.9

4.1

1.6

.3

26.2

28.7

22.2

19.1

2.5

17.2

1.67

1.14

31.3

21.2

25.9

3.4 
Table 2

Fant1y Characteristics of Sample

Varlable

Value

Frequency

Percent Mean S.D.

* Cht1dren

$\begin{array}{rr}1 & 17 \\ 2 & 120 \\ 4 & 102 \\ 5 & 18 \\ 6 & \\ 7 & 8\end{array}$

17

5.3

2.87

1.29

102

37.5

31.9

40

12.5

$18 \quad 5.6$

$8 \quad 2.8$

$6 \quad 1.6$

Yrs. to

Closest Sib.

$\begin{array}{rrrrr}0 & 15 & 4.7 & 2.95 & 2.06 \\ 1 & 50 & 15.6 & & \\ 2 & 99 & 30.9 & & \\ 3 & 64 & 20.0 & & \\ 4 & 33 & 10.3 & & \\ 5 & 21 & 6.6 & & \\ 6 & 10 & 3.1 & & \\ 27 & 22 & 6.8 & & \end{array}$

Participant 's

S1b. Pasition

-Only Child

17

5.3

1.97

.98

$-01 d e s t$

105

32.8

Hiddle

-Youngest

64

20.0

130

40.6

Fan. Comp.

Growing Up

-2 Parents \&

Natural Sibs

225

70.3

1.12

1.91

-2 Parents \&

Unrelated Sibs

4

1.2

-2 Parents \&

No Sibs

1

3.1

-1 Parent

2

10

14.9

-Blended Family

48

4.7

-Remarried Par.

15

3.7

Parents Hork Out of Home Past 5 Yrs.

-Both Emplojed

69.4

.39

.71

- Father Brployed

68

21.2

3.7

-Neither Employed

10

3.1

\#dopted or foster sibs 
selection bias, the students were not told that the study focused specifically on sibling relationships, jealousy, and favoritism.

After a brief introduction to the study, participants filled out consent forms (See Appendix I). The study then began, with the instruments administered in the following order: 1) Demographic and Family Information (See Appendix J), 2) Sibling and Parent-Initiated vignettes in random order, 3) Rosenberg Self-Esteem Scale, 4) Family Atmosphere Questionnaire, 5) Sibling Relationship Questionnaire (with random assignment to rating oldest, youngest, or closest in age sibling), 6) Personal Authority within the Family system Questionnaire, 7) Relevance of Domains, and 8) Favoritism Status Questions.

\section{Instruments}

The study used a combination of direct and indirect methods to assess jealousy and favoritism.

1) Vignettes- To maximize expressions of jealousy and minimize inhibitions from social desirability which have plagued this area of research (Clanton \& Kosins, 1991), vignettes were used as a projective technique to elicit jealous responses. Vignettes are widely viewed as an acceptable method of social psychological research with sensitive topics such as rape and jury behavior (Lott, 1990 personal communication). They have been used in several 
non-sibling studies of jealousy (Hansen, 1991; Hupka \& Eshett, 1988; Bers \& Rodin, 1984; Buunk, 1980,).

The researcher designed sixteen vignettes; eight representing sibling-initiated comparisons and eight representing parent-initiated comparisons (See Appendix A \& B). The vignettes were based on Ross \& Milgram's (1982) study in which they interviewed 75 adults aged 22 to 93 and identified five domains that most frequently generate sibling rivalry and favoritism. The five areas cited in their study were, in order of frequency: 1) achievement, 2) physical attractiveness, 3) intelligence, 4) interpersonal competence, and 5) maturity. In the proposed study, achievement is overrepresented by four vignettes reflecting different sub-areas (athletics, artistic ability, wealth, and occupational achievement), in order to sample from areas of more varied "relevance" to facilitate testing the selfevaluation maintenance model. Additionally, Ross \& Milgram found that achievement was "the dimension of rivalry par excellence" which engendered the most frequent and intense jealous reactions from siblings.

Participants reviewed the vignettes and rated how they would feel, think, and behave if they were in each situation (See Appendix C\&D). Response sets tapped affective, cognitive, and behavioral reactions based on the previously cited definition of jealousy as a complex response made up of these three components (White \& Mullen, 1989). 
Selection of the specific emotions, thoughts, and behaviors assessed was based on a literature review of romantic jealousy reactions. Studies show that general upset, hurt, anger, and sadness are some of the most frequent responses to romantic jealousy (Bringle \& Bunk, 1986). Other responses such as fear and sexual arousal seemed less relevant to sibling jealousy. Some typical cognitive reactions include attempting to appraise or understand the event, and using coping mechanisms of denial, introspection, and derogation or devaluation of the source or rival (White \& Mullen, 1989). Buunk (1982) classifies the three typical behavioral responses to jealousy as 1) avoidance (of the relationship), 2) reappraisal, and 3) communication. Salovey \& Rodin (1988) emphasize the use of self-esteem maintenance strategies such as self-reliance, selfbolstering, and selective ignoring.

A synthesis of the relevant reactions cited in these studies formed the basis for the seven items measuring jealous responses in this study. Jealousy scores were calculated by averaging the responses to questions about emotional, cognitive, and behavioral reactions to the vignettes. Of course, an important limitation of this method was that the scores only reflected anticipated jealousy based on the participants' projections of how they would react and not their real-life responses. For this reason, 
direct measures of jealousy and favoritism also were administered.

One additional item assessed the perceived fairness of the situations portrayed in the vignettes. This item served as a covariate to partial out the effects of general social justice comparisons. All items were measured on a Likerttype scale.

A high score on this scale indicated high jealousy.

2) Relevance of Domains- To assess the relevance of the domains, participants were asked to rate on a Likert-type scale how important each area (i.e. athletics, attractiveness, etc.) was to their self-definition (See Appendix E) .

3) Self Esteem- This variable was measured by the Rosenberg Self-Esteem Scale (Rosenberg, 1965), (See Appendix F). This instrument is a well-established, widely used ten-item scale with a Likert-style format. Alpha coefficients for the scale range from .77 to .87 . Test-retest reliability is .85 at two weeks and .63 at 7 months (Wylie, 1989). Construct, predictive, convergent, and discriminant validity have been widely tested for this scale (Wylie, 1989). A high score on the Rosenberg Self-Esteem scale indicates high self-esteem. 4) Family Atmosphere- This was assessed by the Family Atmosphere Questionnaire, a 5 item measure with a Likerttype response format (See Appendix G). The instrument is designed to measure an individual's perception of family 
unity, security, general happiness, and the amount of conflict in the family. Cronbach alpha for the scale is .87, and test-retest reliability is .92 (Kinniard \& Gerrard, 1986). The scale has been shown to differentiate between college-age women from intact versus divorced and reconstituted families. A high score on the Family Atmosphere Questionnaire indicates a poor family atmosphere. 5) Sibling Warmth/Closeness- This variable was assessed by 21 items comprising subscales of the sibling Relationship Questionnaire (Furman \& Buhrmester, 1985), (See Appendix H). A high score on this scale indicates high levels of sibling warmth and closeness. The SRQ is a 48-item Likert-type questionnaire designed to measure perceptions of relationships between siblings. Factor analysis has revealed warmth/closeness to be one of the four primary constructs within the instrument. This construct consists of items from the following subscales: prosocial, affection, companionship, similarity, intimacy, admiration of sibling, and admiration by sibling. Cronbach alpha for the subscales of the SRQ averages .80 , with no subscale receiving an alpha less than .63 . Test-retest reliability at ten days averages .71. Perceptions of family members correlate at least .57. 6) Sibling Rivalry and conflict- In addition to the indirect measures of jealousy assessed by the vignettes, direct measures of sibling rivalry and conflict were assessed by the SRQ (Furman \& Buhrmester, 1985). The Sibling Rivalry 
Scale of the SRQ is a 6 item scale consisting of 2 subscales: maternal partiality and paternal partiality. Deviation scores on these scales measure the degree of partiality shown toward siblings. When the items are summed, a high score on the sibling Rivalry Scale indicates partiality toward the respondent and a low score indicates partiality toward the respondent's sibling. The sibling Conflict Scale of the SRQ consists of 9 items measuring antagonism, competition, and quarreling. A high score on the sibling conflict scale indicates high conflict.

7) Personal Authority within the Family System- This variable was assessed by the 84 -item Personal Authority in the Family System Questionnaire (PAFS-Q), Version C (Bray, Williamson, \& Malone, 1984). The PAFS-Q is designed to measure levels of personal authority within the family system, or the ability to function autonomously while still maintaining healthy ties to the family. Subscales within the PAFS-Q are designed to measure Intergenerational Intimacy, Intergenerational Individuation, Intergenerational Intimidation (the need to live up to parents' expectations and inability to assert self with parents), Intergenerational Triangulation (coalition with one parent against the other), Peer Intimacy, and Peer Individuation. coefficient alphas for the PAFS-Q range from .76 to .95 . Test-retest reliability at 2-week intervals ranges from .71 to .95. Support for the construct validity of the scale 
comes from correlations between its subscales and the Dyadic Adjustment Scale and the Cohesion scale of the FACES (Bray, Williamson, \& Malone, 1984). The scale has shown good discriminant and concurrent validity (Anderson \& Fleming, 1986; Fleming \& Anderson, 1986; Bray, Williamson, \& Malone, 1984).

Version $C$ of the PAFS-Q was developed specifically for college students. Factor analysis with 360 undergraduates supports the factor structure and the independence of the subscales with this population. Version $C$ represents a revision of the original scale with a higher cutoff for factor loadings and more refined subscale construction. High total scores on the PAFS-Q, Version $C$ indicate greater personal authority within the family system, as evidenced by high parental and peer intimacy and individuation, and low intergenerational intimidation and triangluation. High scores on the Intergenerational Intimacy subscale indicate more intimacy, high scores on the Intergenerational Individuation subscale indicate more individuation, high scores on the Personal Authority subscale indicate more personal authority, high scores on the Intergenerational Intimidation subscale indicate less intimidation, high scores on the Intergenerational Triangulation subscale indicate less triangulation, high scores on the Peer Intimidation subscale indicate more intimacy, and high 
scores on the Peer Individuation subscale indicate more individuation.

9) Favoritism Status Questions- A few questions directly. assessing favoritism in the respondent's family were asked at the end of the study (See Appendix H). These questions were combined with responses to the Parental Partiality subscales of the SRQ to categorize respondents as favorites, non-favorites (another sibling favored), or neutrals (no sibling favored) for further hypothesis testing.

\section{DATA ANALYSIS}

The first step in the data analysis was a factor analysis of the jealousy responses for the vignettes. The purpose of the factor analysis was to 1) summarize the cognitive, affective, and behavioral aspects of the 7 jealousy items across the 16 vignettes, 2) to identify the underlying structure within the jealousy items, and 3) to enter the component(s) as the dependent variable for hypothesis testing.

An exploratory principal components analysis (PCA) $(n=320)$ was done to analyze the underlying structure of the 7 jealousy items combined with the 16 vignettes (i.e. $7 \times 16=$ 112 variables). This analysis extracted 11 factors with eigenvalues greater than 2 , and accounting for a total of $47.5 \%$ of the variance. After varimax rotation, the factors could be interpreted as representing three of the jealousy 
items and eight of the vignettes. Subsequent factor analyses with the two subsets of sibling and parentinitiated jealousy vignettes respectively, showed similar patterns, with a combination of several items and key vignettes comprising factors. In other words, an important finding of these early analyses was that the vignettes themselves comprised factors. This indicates that certain situations created highly uniform or intercorrelated jealousy reactions (i.e., jealousy was highly situational).

An exploratory PCA was done to look specifically at the factor structure within the 7 items of the jealousy scale collapsed across the 16 vignettes. After varimax rotation, a two factor solution emerged with 5 of the items loading on one primary factor with an eigenvalue of 3.50 . This main factor accounted for $50.0 \%$ of the variance. A second factor consisted of loadings from the remaining 2 items, accounting for an additional $17.8 \%$ of the variance. The scree plot suggested that a one factor solution was optimal. An identical pattern was found for separate PCA's done on the 7 jealousy items for the two subsets of sibling and parent-initiated jealousy vignettes, respectively.

A PCA with a one factor solution and varimax rotation was conducted on the 7-item jealousy scale collapsed across the 16 vignettes. This analysis extracted one factor with an eigenvalue of 3.50 , accounting for $50.0 \%$ of the variance. Table 3 lists the factor loadings for the five items that 
loaded highly on this factor. An identical pattern of results was found for separate one-factor PCA's conducted on the jealousy items for the two subsets of sibling and parent- initiated jealousy vignettes. Based on these results, the five items loading on the one main factor were retained to comprise the jealousy scores for hypothesis testing. The resulting 5 item jealousy scale had a Chronbach alpha of .87 when collapsed across the 16 vignettes (alpha $=.88$ for the 8 sibling vignettes, and alpha $=.86$ for the 8 parent vignettes).

Table 3

One Factor PCA on 7 Jealousy Items $(n=320)$

Jealousy Item Factor Loading

Hurt .93

Upset .93

Angry .92

Avoid or Pull Away .70

Try to Figure out Reasons $-.66$

Tell Self It Doesn't Matter .00

Talk to Parent/Sibling .00

Eigenvalue 3.50

Percentage of Variance 50.0 
Hypothesis testing was done with a combination of multiple regression, $t$ tests and ANOVA. A within-groups repeated measures $t$ test was done to test the hypothesis that parent-initiated comparisons create more jealousy than sibling-initiated comparisons. A follow-up ANCOVA was done to assess the effects of these comparisons with perceived fairness partialled out.

To test the hypothesis that parent-initiated comparisons would be more global and less domain-specific than sibling-initiated comparisons, $t$ tests assessing within-groups differences on the higher importance versus lower importance domains were done for the parent and sibling vignettes.

Multiple regression analyses assessed the relationship between jealous reactions to the vignettes (dependent variable) and personal authority within the family system, self-esteem, closeness in sibling age, intactness of family, and sibling warmth, and family atmosphere (independent variables). These analyses were repeated using direct measures of sibling rivalry and sibling conflict from the SRQ as the dependent variables. The ability of family constellation variables to predict levels of jealousy was also assessed with multiple regression.

Finally, a one-way ANOVA with two levels tested the hypothesis that favorites have higher levels of self-esteem than non-favorites. A one-way ANOVA with three levels was 
used to test the hypothesis that favorites and non-favorites have lower levels of personal authority within the family system than neutrals.

\section{RESULTS}

Sibling Versus Parent-Initiated Comparisons

A within-subjects repeated measures t-test was done to assess the differences in mean jealousy scores for the sibling-initiated versus parent-initiated jealousy vignettes. The independent variable was the 2 levels of types of comparisons or vignettes, and the dependent variable was the jealousy score on the 5 item scale derived from the PCA. The purpose of this analysis was to test the hypothesis generated by the SEM model that parent-initiated comparisons create more jealousy than sibling-initiated comparisons.

Results were that parent-initiated comparisons produced significantly higher jealousy scores than sibling-initiated comparisons $(t(319)=50.01, p<.0001)$ (See Table 4). These findings supported the prediction based on the SEM model that parental comparisons would be more salient, and therefore more likely to create jealousy. 
Table 4

Within-Subjects Repeated Measures T-Test on Mean Jealousy for Sibling Versus Parent-Initiated Vignettes $(\mathrm{N}=320)$

\begin{tabular}{lcccc} 
Source & Mean & S.D. & Std. Error & T \\
Sibling Vignettes & 132.37 & 17.55 & .981 & $50.01 * * * *$ \\
Parent Vignettes & 89.59 & 14.06 & .786 & \\
Difference & 42.78 & 15.30 & .855 & \\
$* * * * \mathrm{p}<.0001$ & & & & \\
\hline
\end{tabular}

Since the parent-initiated situations involved favoritism, and therefore could be viewed as more unfair than the sibling-initiated situations, a follow-up ANCOVA was done to assess the effects of sibling versus parentinitiated comparisons with perceived fairness partialled out. Perceived fairness was measured by an additional item at the end of the jealousy scale administered after each vignette (See Appendix C \& D).

A one-way within-groups ANCOVA with two levels was done to assess the differences between mean jealousy scores (dependent variable) by type of vignette (independent variable) with perceived fairness (covariate) partialled out. Results were that the parent-initiated vignettes produced significantly higher levels of jealousy than the sibling-initiated vignettes, even with the effects of 
perceived fairness partialled out $(F(1,319)=2501.37, p<$ $.0001)$.

Table 5 lists the mean jealousy scores by type of vignette. Again, the results show consistently higher jealousy scores for the parent-initiated comparisons. Vignettes portraying comparisons on physical attractiveness, social competence, and athletic achievement produced the highest levels of jealousy for both sibling and parental comparisons.

Responses to the parent-initiated comparisons yielded a narrower range of mean scores and smaller standard deviations, indicating less variability in jealousy than with the responses to the sibling-initiated comparisons. This pattern lends support for the study's hypothesis that parent-initiated comparisons are more global and less domain-specific than sibling comparisons.

To further test the hypothesis that parent-initiated comparisons produce more global and less specific jealousy responses, t-tests were done comparing responses on domains of high and low importance to the respondents. It was expected that there would be significant differences in mean jealousy for high and low importance sibling vignettes. However, no significant differences were expected for high and low importance parent vignettes because any comparison that was important to the parent would become salient and important to the sibling. 
Table 5

Mean Jealousy Scores By Type of Vignette

Sibling-Initiated Comparisons

Physical Attractiveness

16.5

3.5

Social Competence

16.0

3.6

Athletic Achievement

14.5

3.6

Maturity

13.9

3.6

Intelligence

13.7

3.5

Wealth

11.9

3.2

Occupational Achievement

10.9

3.2

Artistic Achievement

10.3

2.9

TOTAL $=107.7$

Mean $=13.5$

Mean S.D. $=3.4$

Parent-Initiated Comparisons

Physical Attractiveness

19.5

2.5

Social Competence

19.6

2.7

Athletic Achievement

19.6

2.7

Maturity

18.0

2.4

Intelligence

19.1

2.7

Wealth

19.2

2.6

Occupational Achievement

16.3

3.2

Artistic Achievement

19.1

3.7

TOTAL $=150.4$

Mean $=18.8$

Mean S.D. $=2.8$ 
Table 6 lists the mean ratings of importance for the 8 domains represented by the vignettes, as assessed by a separate scale asking how important each domain was to the participants (See Appendix E). Based on these ratings, vignettes were divided into two groups of 1) higher importance vignettes (including social competence, physical attractiveness, intellectual achievement, maturity, and occupational achievement) and, 2) lower importance vignettes (including wealth, athletic, and artistic achievement).

Table 6

Mean Ratings on Importance of Jealousy Domains

Domain

Social competence

Intellectual Achievement

Physical Attractiveness

Maturity

Occupational Achievement

Wealth- Achievement

Athletic Achievement

Artistic Achievement
Mean Rating*

$$
4 \cdot 4
$$

$4 \cdot 4$ .84

$4 \cdot 3$ .76

$4 \cdot 2$

.91

$4 \cdot 1$

.96

3.7

1.00

3.4

1.28

2.4

1.27

* Higher numbers indicate higher levels of importance to the respondent on a scale of 1 to 5 . 
A within-subjects t-test was done to assess the differences in mean jealousy scores for the sibling vignettes on domains of higher versus lower importance to the subjects. The independent variable was the two types of sibling vignettes (i.e., high importance vs. low importance) and the dependent variable was the jealousy score. Results were that the sibling vignettes on domains of higher importance produced significantly greater levels of jealousy (mean= 14.2) than those on domains of lower importance $(\operatorname{mean}=12.3)(t(319)=-17.99, \mathrm{p}<.001) \quad($ See Table 7$)$. In other words, subjects appeared to make specific discriminations between high and low importance domains, as expected.

Table 7

Within Subjects T-Test on Mean Jealousy Scores for High Versus Low Importance Sibling-Initiated Jealousy Vignettes $(\mathrm{N}=320)$

\begin{tabular}{lcccc}
\hline Source & Mean & SD & Std. Err. & T \\
\hline High Importance & 14.18 & 2.38 & .133 & $-17.99 * * \star$ \\
Low Importance & 12.25 & 2.40 & .134 & \\
Difference & 1.931 & 1.92 & .107 & \\
$* * * \mathrm{p}<.001$ & & & & \\
\hline
\end{tabular}


A within-subjects $t$-test was done to assess the differences in mean jealousy scores for the parent-initiated jealousy vignettes on domains of higher versus lower importance to the subjects. In this case, the hypothesis was that since jealousy would be more global for parental comparisons, there would be no significant differences between responses to high and low importance vignettes. Surprisingly, results were that the parent-initiated jealousy vignettes on domains of lower importance produced significantly greater levels of jealousy (mean= 19.3) than those on domains of higher importance (mean= 18.5) (t $(319)=$ $8.21, \mathrm{p}<.001$ ) (See Table 8).

Table 8

Within Subjects T-Test on Mean Jealousy Scores for High Versus Low Importance Parent-Initiated Jealousy Vignettes $(\mathrm{N}=320)$

\begin{tabular}{lcccc}
\hline \multicolumn{1}{c}{ Source } & Mean & SD & Std. Err. & T \\
\hline High Importance & 18.51 & 1.96 & .110 & $8.21 * * *$ \\
Low Importance & 19.30 & 1.93 & .108 & .097 \\
Difference & -.797 & 1.74 & & \\
$* * * \mathrm{p}<.001$ & & & &
\end{tabular}


Correlates of Jealousy

The next part of the study explored possible correlates of sibling jealousy. A standard multiple regression was done to assess the relationship between several key variables and jealousy. Self-esteem, family atmosphere, sibling warmth, number of years to closest sibling, intactness of family, and total PAFS-Q scores were the independent variables, and jealousy score on the vignettes was the dependent variable.

Results of the regression analysis showed that selfesteem, family atmosphere, sibling warmth, number of years to closest sibling, intactness of family, and total PAFS-Q scores did not contribute significantly to the prediction of global sibling jealousy across vignettes $(F(6,212)=1.247$, p<.284 N.S.). Non-significant results were obtained for further regression analyses with sibling-initiated jealousy $(F(6,212)=1.38, p<.222$ N.S.) and parent-initiated jealousy $(F(6,212)=.640, p<.698$ N.S. $)$.

since vignettes were used as an indirect projective technique to elicit jealous responses, the next step was to assess the relationship between the selected variables and direct measures of jealousy within the subjects' own families. The multiple regression analyses were repeated with self-esteem, family atmosphere, years to closest sibling, intactness of family, sibling warmth, and personal authority within the family system as the independent 
variables, and scores on the sibling rivalry subscale of the SRQ as the dependent variable. Results were that the selected variables contributed significantly to the prediction of sibling rivalry within the subjects' own families $(F(6,212)=10.82 * * * *, p<.0001)$. Table 9 lists the unstandardized and standardized regression coefficients and the $T$ values for this analysis. Overall, this set of variables accounted for $23 \%$ ( $21 \%$ adjusted) of the variance in sibling rivalry scores.

Table 9

Standard Multiple Regression of Selected Variables on Sibling Rivalry

\begin{tabular}{|c|c|c|c|c|}
\hline Variable & $\mathrm{B}$ & Beta & $\mathrm{T}$ & $\mathrm{F}$ \\
\hline Family Atmosphere & .126 & .173 & $2.12 *$ & $10.82 * * * *$ \\
\hline Yrs. to closest sib. & .170 & .106 & 1.74 & \\
\hline Self Esteem & -.018 & -.032 & -.499 & \\
\hline Family Intactness & .567 & .074 & 1.16 & \\
\hline sibling Warmth & -.053 & -.269 & $-4.00 * * * *$ & \\
\hline PAFS-Q Total score & -.012 & -.117 & $-1 \cdot 36$ & \\
\hline $\mathrm{R}$ Squared $=.234$ & Adjusted & $\mathrm{R}$ Squared= & $=.213$ & $\mathrm{R}=.484$ \\
\hline$* * * * p<.0001$ & & & & \\
\hline$p<.05$ & & & & \\
\hline
\end{tabular}


Sibling warmth $(T(6,212)=-4.00 * * * *, p<.0001)$ and family atmosphere $(T(6,212)=2.12 *, \mathrm{p}<.05)$ were the best predictors of sibling rivalry, and both were significant predictors. Low sibling warmth was associated with high sibling rivalry, and high family conflict was associated with high sibling rivalry.

A multiple regression analysis was done to assess the relationship between self-esteem, family atmosphere, years to closest sibling, intactness of family, sibling warmth, and personal authority within the family structure and scores on the sibling conflict subscale of the SRQ. Results were that this set of variables contributed significantly to the prediction of sibling conflict $(F(6,213)=9.456$, $\mathrm{p}<.0001)$. Overall, this combination of variables accounted for $21 \%$ ( $19 \%$ adjusted) of the variance in sibling conflict. Table 10 lists the detailed results of this analysis.

Sibling warmth $(T(6,213)=-5.70 * * * *, p<.0001)$, total $\operatorname{PAFS}-\mathrm{Q}$ score $(\mathrm{T}(6,213)=-2.73 * * *, \mathrm{p}<.01)$, and family atmosphere $(T(6,213)=-2.11 *, p<.05)$ were the strongest predictors of sibling conflict, and each was a significant predictor. Less sibling warmth, lower personal authority within the family system, and more positive family atmosphere were associated with greater sibling conflict. 
Table 10

standard M.R. of selected Variables on Sibling conflict

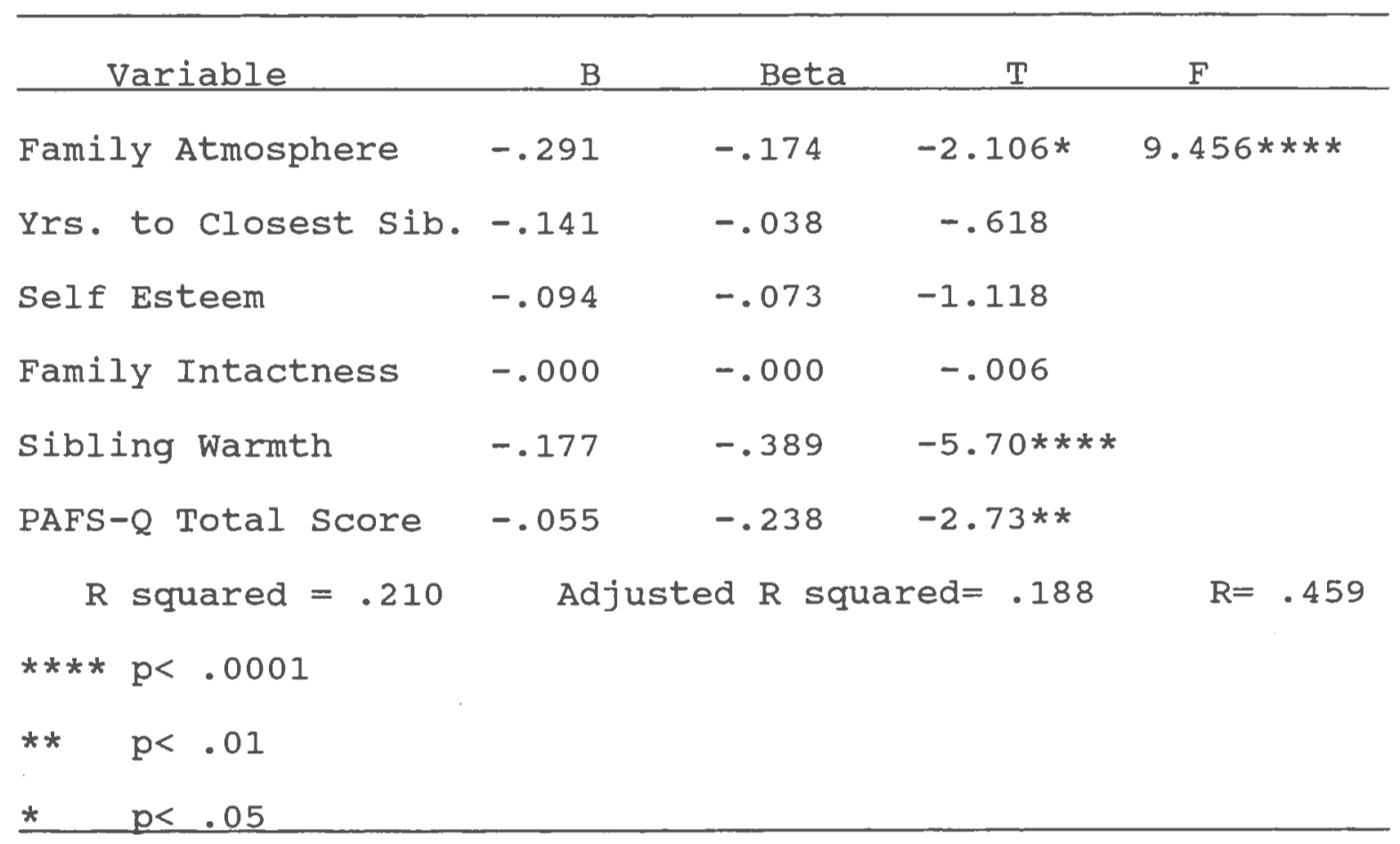

Personal Authority within the Family system and Jealousy

Multiple regression analyses were done to clarify which subscales of the PAFS $Q$ Q were the best predictors of jealousy on the vignettes. A standard multiple regression analysis assessed the relationship between subscales of the PAFS-Q and global jealousy in reaction to the vignettes. Results showed that the PAFS-Q subscales were significant predictors of jealous reactions $(F(7,272)=3.512 * *, p<.01)$. Altogether, $8 \%$ ( $6 \%$ adjusted) of the variance in jealousy scores could be predicted by knowing subscales scores on the PAFS-Q (See Table 11). 
Table 11

standard Multiple Regression of PAFS-Q Subscales on Jealousy

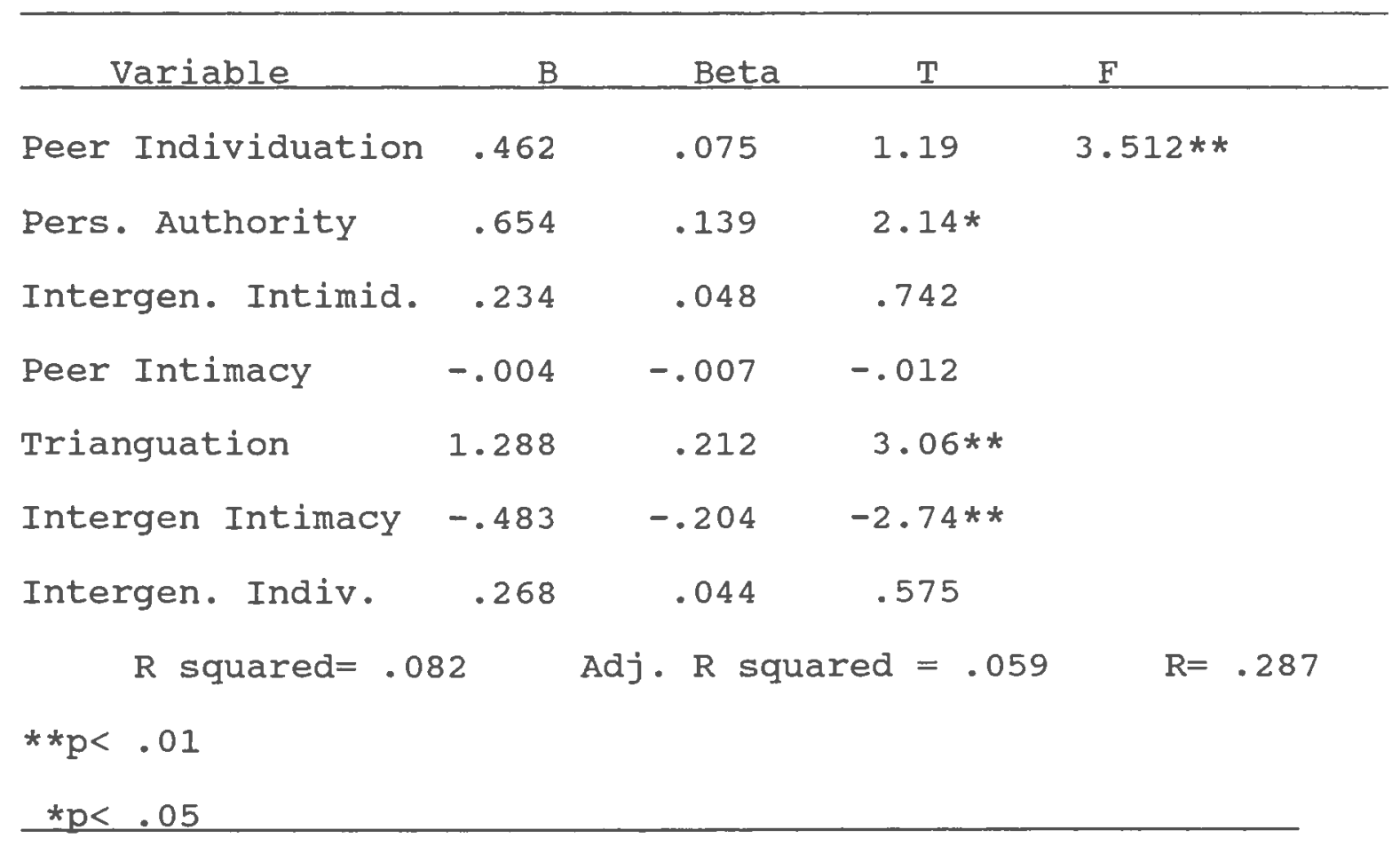

Intergenerational triangulation, intergenerational intimacy, and personal authority within the family system were the best predictors of jealousy, and each was a significant predictor (triangulation $(T(7,272=3.06 *$, $p<$ .01), intergenerational intimacy $(\mathrm{T}(7,272)=-2.74 * *, \mathrm{p}<$ $.01)$, personal authority $(T(7,272)=2.14 *, p<.05)$. Less triangulation, lower intergenerational intimacy, and higher personal authority within the family system predicted lower levels of jealousy. 
Further regression analyses were done to clarify which subscales of the PAFS-Q were the best predictors of sibling versus parent-initiated jealousy on the vignettes. Results were that the PAFS-Q subscales contributed significantly to the prediction of sibling-initiated jealousy $(F(7,272)=$ $3.677, \mathrm{p}<.001 * * *$ ) (See Table 12).

Table 12

Standard Multiple Regression of PAFS-Q Subscale Scores on Sibling- Initiated Jealousy

\begin{tabular}{|c|c|c|c|c|c|}
\hline Subscale & $\mathrm{B}$ & Beta & $\mathrm{T}$ & \multicolumn{2}{|l|}{ F } \\
\hline Peer Individuation & .402 & .105 & 1.66 & 3.677 & * * \\
\hline Personal Authority & .335 & .115 & 1.76 & & \\
\hline Triangulation & .719 & .191 & $2.76 * *$ & & \\
\hline Peer Intimacy & -.075 & -.024 & .399 & & \\
\hline Intgen. Intimidation & .343 & .112 & 1.75 & & \\
\hline Intergen. Intimacy & -.228 & -.155 & $-2.08 *$ & & \\
\hline Intergen. Individ. & .048 & .013 & .167 & & \\
\hline $\mathrm{R}$ squared $=.086$ & Adjusted & $R$ squared= & $=.062$ & $R=$ & .294 \\
\hline$\star * \mathrm{p}<.01$ & & & & & \\
\hline$* \quad p<.05$ & & & & & \\
\hline
\end{tabular}


Overall, $8 \%$ ( $6 \%$ adjusted) of the variance in siblinginitiated jealousy could be explained by knowing subscale scores on the PAFS-Q. Here, triangulation $(T(7,272)=$ $2.76 * *, p<.01)$, and intergenerational intimacy $(T(7,272)=$ $-2.08 *, p<.05)$ were the best predictors of siblinginitiated jealousy, and both were significant predictors. Less intergenerational triangulation, and less intergenerational intimacy predicted less jealousy. PAFS-Q subscales were similarly found to contribute significantly to the prediction of parent-initiated jealousy on the vignettes $(F(7,272)=2.280 *, p<.05)$ (See Table 13). overall, $5 \%$ ( $3 \%$ adjusted) of the variance in parentinitiated jealousy could be predicted by knowing subscale scores on the PAFS-Q. For parent-initiated jealousy, intergenerational intimacy $(T(2,272)=-2.75 *, p<.01)$, and personal authority $(T(2,272)=1.99 *, \mathrm{p}<.05)$ were the best predictors, and each was a significant predictor. Less intergenerational intimacy, less triangulation, and greater personal authority within the family system were associated with lower levels of parent-initiated jealousy. 
Table 13

Standard Multiple Regression of PAFS-Q Subscales on ParentInitiated Jealousy

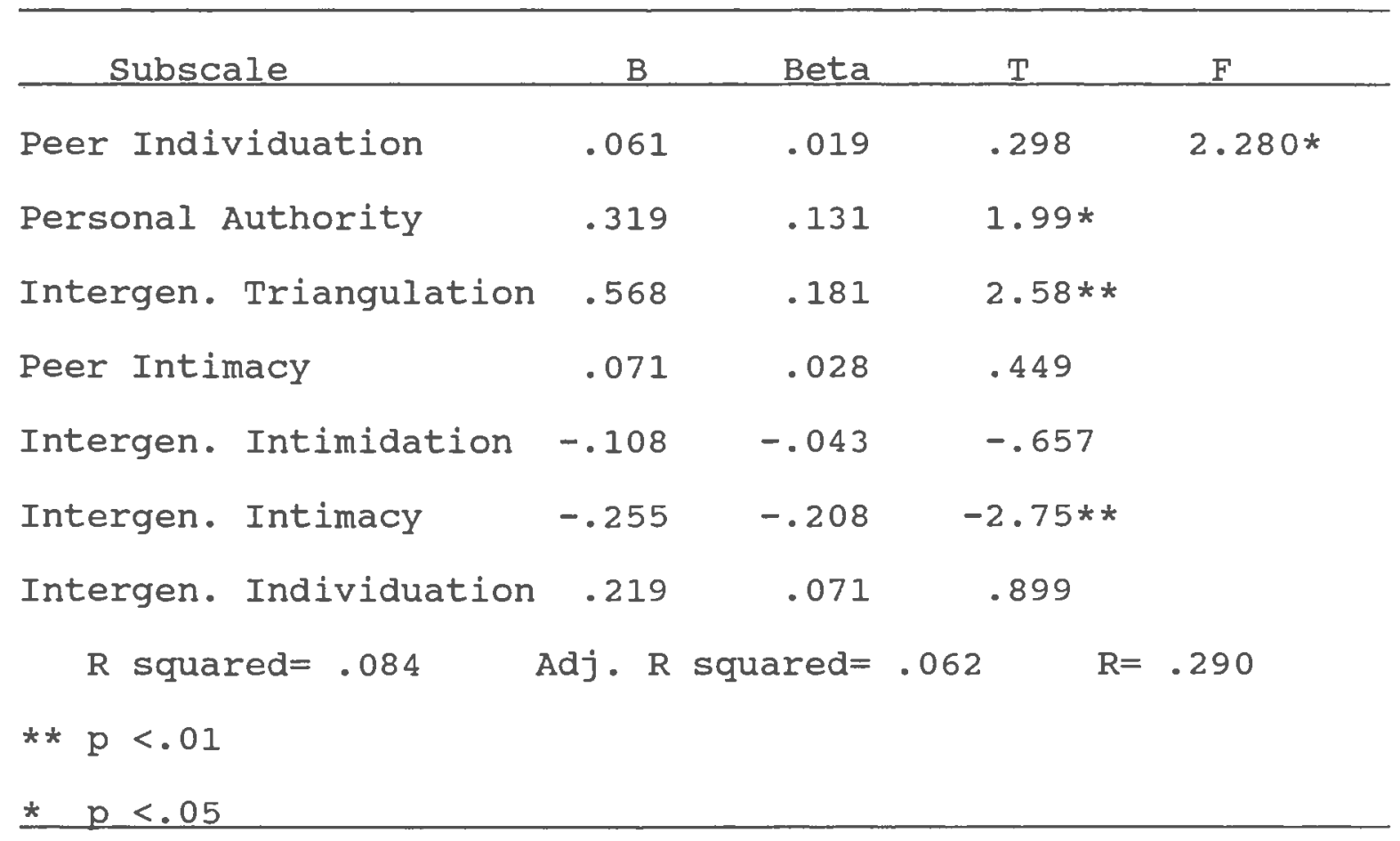

The regression analyses were repeated using direct measures of sibling rivalry and conflict from the SRQ. Results were that the PAFS-Q subscales significantly contributed to the prediction of sibling rivalry within the subjects own families $(F(7,262)=8.453 * * * *, p<.0001)$. Overall, $18 \%$ (16\% adjusted) of the variance in sibling rivalry could be predicted by knowing PAFS-Q subscale scores (See Table 14). 
Table 14

Standard Multiple Regression of PAFS-Q Subscales on Sibling Rivalry

\begin{tabular}{|c|c|c|c|c|}
\hline Subscale & B & Beta & $\mathrm{T}$ & F \\
\hline Peer Individuation & -.028 & -.050 & -.818 & $8.432 * * * *$ \\
\hline Personal Authority & .012 & .027 & .433 & \\
\hline Triangulation & -.090 & -.164 & $-2.465 *$ & \\
\hline Peer Intimacy & .070 & .152 & $2.581 * *$ & \\
\hline Intergen. Intimidation & .000 & .011 & .176 & \\
\hline Intergen. Intimacy & -.031 & -.142 & $-1.991 *$ & \\
\hline Intergen. Individ. & -.111 & -.204 & $-2.723 * *$ & \\
\hline $\mathrm{R}$ squared $=.183$ & Adjusted & $\mathrm{R}$ squared & $d=.162$ & $\mathrm{R}=.428$ \\
\hline$* * * * \mathrm{p}<.0001$ & & & & \\
\hline $\mathrm{p}<.01$ & & & & \\
\hline$p<.05$ & & & & \\
\hline
\end{tabular}

For sibling rivalry, intergenerational individuation $(T(7,272)=-2.72 * *, p<.01$, peer intimacy $(T(7,272)=$ $2.58 * *, p<.01)$, triangulation $(T(7,272)=-1.99, p<.05)$, and intergenerational intimacy $(T(7,272)=-1.99 *, p<.05)$ were the best predictors, and all were significant predictors. Less intergenerational individuation, less intergenerational intimacy, more triangulation, and more peer intimacy were associated with more sibling rivalry. 
A standard multiple regression was done to assess the relationship betweeen subscales of the PAFS-Q and sibling conflict, as measured by the SRQ. Results were that the PAFS-Q subscales contributed significantly to the prediction of sibling conflict $(F(7,263)=5.475 * * * *, p<.0001)$. (See Table 15) .

Table 15

Standard Multiple Regression of PAFS-Q Subscales on Sibling Conflict

\begin{tabular}{|c|c|c|c|c|c|}
\hline Subscale & B & Beta & $\mathbf{T}$ & \multicolumn{2}{|l|}{$F$} \\
\hline Peer Individuation & -.048 & -.037 & -.592 & \multirow{7}{*}{\multicolumn{2}{|c|}{$5.474 * * * *$}} \\
\hline Personal Authority & -.083 & -.086 & 1.319 & & \\
\hline Triangulation & -.271 & -.216 & $3.150 * *$ & & \\
\hline Peer Intimacy & -.000 & -.000 & -.099 & & \\
\hline Intergen. Intimid. & -.205 & -.202 & $3.159 * *$ & & \\
\hline Intergen. Intimacy & .063 & .128 & 1.738 & & \\
\hline Intergen. Individ. & -.058 & -.047 & -.612 & & \\
\hline $\mathrm{R}$ squared $=.127$ & Adjusted & $\mathrm{R}$ Squared= & $=.104$ & $\mathrm{R}=$ & .357 \\
\hline$* * * * p<.0001$ & & & & & \\
\hline$p<.01$ & & & & & \\
\hline
\end{tabular}

Overall, $13 \%$ ( $10 \%$ adjusted) of the variance in sibling conflict could be predicted by knowing subscale scores on the PAFS-Q. Intergenerational triangulation $(T(77,263)=$ 
$-3.15) * * p<.01$ ), and intergenerational intimidation ( $T$ $(7,263)=-3.16 * *, p<.01)$ were the best predictors of sibling conflict, and both were significant predictors. More intergenerational triangulation and more intergenerational intimidation were associated with higher sibling conflict.

Family Constellation Variables and Jealousy

A standard multiple regression was done to assess the relationship between family constellation variables and jealousy. Since findings have been mixed for correlations between family constellation variables and jealousy in past studies, the purpose of this analysis was to further explore and clarify the relationships among these variables. For this analysis, the predictor variables were number of siblings, sibling position, same-sex versus mixed-sex siblings, years to closest sibling, and intactness of family; and the dependent variable was jealous reactions to the vignettes. Results showed that this combination of family constellation variables did not contribute significantly to the prediction of jealousy $(F(5,298)=$ $1.67, \mathrm{p}<.32$ N.S.). Likewise, a standard multiple regression of family constellation variables on siblinginitiated jealousy was non-significant $(F(5,289)=1.167$, p .32 N.S.); and a standard multiple regression of family 
constellation variables on parent-initiated jealousy was non-significant $(F(5,289)=.579, p<.71$, N.S.). In summary, there was no significant relationship between family constellation variables and sibling jealousy as measured by the vignettes.

The regression analysis was repeated using direct measures of sibling rivalry and conflict from the SRQ. Results were that family constellation variables contributed significantly to the prediction of sibling rivalry in the subjects' own families ( $F(5,288=3.14 * *, p<.01)$ (See Table 16).

Table 16

Standard Multiple Regression of Family Constellation Variables on Sibling Rivalry

\begin{tabular}{|c|c|c|c|c|c|}
\hline Variable & B & Beta & $\mathrm{T}$ & \multicolumn{2}{|l|}{$F$} \\
\hline Same sex siblings & -.720 & -.109 & -1.88 & \multicolumn{2}{|c|}{$3.135 * *$} \\
\hline Years to closest Sib & .148 & .090 & 1.55 & & \\
\hline Number of Siblings & -.070 & -.026 & .457 & & \\
\hline Birth order & -.338 & -.094 & -1.63 & & \\
\hline Intactness of Family & .976 & .129 & $2.21 *$ & & \\
\hline $\mathrm{R}$ squared $=.051$ & Adjusted & $\mathrm{R}$ squared $=$ & .035 & $\mathrm{R}=$ & .227 \\
\hline$* * \mathrm{p}<.01$ & & & & & \\
\hline$\star p<.05$ & & & & & \\
\hline
\end{tabular}


Overall, $5 \%$ ( $3 \%$ adjusted) of the variance in sibling riavlry could be predicted from knowing data on the family constellation variables. Intactness of family structure ( $T$ $(5,288)=2.21 *, p<.05)$ was the only significant predictor of sibling rivalry among the family constellation variables. Non-intactness of the family (i.e., parents not living together) was associated with higher levels of sibling rivalry.

A standard multiple regression analysis was done to assess the relationship between family constellation variables and sibling conflict, as measured by the SRQ. Results were that family constellation variables contributed significantly to the prediction of sibling conflict within the subjects' own families $(F(5,291)=6.63 * * * *, p<.0001)$. Overall, $10 \%$ (9\% adjusted) of the variance in sibling conflict could be predicted by knowing data from the family constellation variables (See Table 17). Birth order (T $(5,291)=-4.39 * * * *, p<.0001)$ and same sex siblings (T $(5,291)=2.74 * *, \mathrm{p}<.01)$ were the best predictors of sibling conflict, and both were significant predictors. Being higher in birth order (i.e. oldest or middle versus youngest child), and having siblings of one's own sex (versus mixed or opposite sex only) were associated with higher levels of sibling conflict. 
Table 17

Standard Multiple Regression of Family Constellation Variables on sibling conflict

\begin{tabular}{lcccc}
\hline Variable & B & Beta & T & F \\
\hline Same Sex siblings & 2.32 & .154 & $2.74 * *$ & $6.627 * * * *$ \\
Years to Closest Sib & -.29 & -.077 & -1.38 & \\
Number of Siblings & -.62 & -.100 & -1.79 & \\
Birth Order & -2.02 & -.245 & $-4.39 * * * *$ & \\
Family Intactness & .33 & .019 & .33 & $\mathrm{R}=.319$ \\
$\mathrm{R}$ squared= .102 & Adjusted $\mathrm{R}$ squared= .086 & & \\
$* * * * \mathrm{p}<.0001$ & & & & \\
$* * \quad \mathrm{p}<.01$ & & &
\end{tabular}

Favoritism

At the conclusion of the study, subjects completed a short questionnaire addressing favoritism in their own families. Results were that $65 \%(n=131)$ of subjects identified a maternal and/or paternal favorite in their family, as compared with $35 \%(n=70)$ who reported no favoritism (See Table 18). When asked who was the favorite, the most frequent response was "myself", with $17 \%(n=34)$ of subjects viewing themselves as their father's favorite, $15 \%$ $(n=31)$ their mother's favorite, and 11\% $(n=23)$ both their mother's and their father's favorite. Viewed from the other 
angle, $21 \%$ of subjects identified other siblings as favorites for both their mother and their father, leaving them as what could be considered "double non-favorites".

Table 18

FAVORITISM STATUS OF SUBJECTS

\begin{tabular}{lcc}
\hline Status & $\mathrm{N}$ & Percent \\
\hline No Favoritism & 70 & $34.8 \%$ \\
Mother's Favorite & 31 & $15.4 \%$ \\
Father's Favorite & 34 & $16.9 \%$ \\
Double Favorite & 23 & $11.4 \%$ \\
Double Non-Favorite & 43 & $21.4 \%$ \\
Total & 201 & $100 \%$ \\
\hline
\end{tabular}

Table 19 gives a detailed breakdown of the favoritism questionnaire responses. Aside from the subjects themselves, older brothers and younger sisters were the most frequently reported maternal favorites; and younger brothers were the most frequently reported paternal favorites.

In response to a question about patterns of favoritism over time, $37 \%$ of the sample reported that "different children have been favored at different times", $21 \%$ reported that "the favorite has always been the same person", and $42 \%$ reported that "no one child had been favored". On a scale of 
Table 19

FAVORITISM QUESTIONNAIRE RESPONSES

1. Who is your mother's favorite?

$\begin{array}{lrr}\text { a. older brother } & \text { frequency } & \text { percent } \\ \text { b. older sister } & 17 & 8.5 \% \\ \text { c. younger brother } & 9 & 4.5 \% \\ \text { d. younger sister } & 9 & 4.5 \% \\ \text { e. myself } & 17 & 8.5 \% \\ \text { f. no one in particular } & 118 & 15.4 \% \\ \text { TOTAL } & 201 & 58.6 \%\end{array}$

2. Who is your father's favorite?
a. older brother
b. older sister
11
$5.5 \%$
c. younger brother
10
$5.0 \%$
d. younger sister
18
$9.0 \%$
e. myself
10
$5.0 \%$
f. no one in particular 118
$16.9 \%$
$58.6 \%$
TOTAL
201
$100 \%$

frequency

percent

3. How much of a problem has favoritism been in your family?

\section{frequency}
a. extreme problem
b.
c. sometimes problem
d.
e. not a problem

TOTAL

9
10
39
33
108

199 percent

$$
\begin{array}{r}
4.5 \% \\
5.0 \% \\
19.6 \% \\
16.6 \% \\
54.3 \%
\end{array}
$$

$100 \%$

4. Which of the following best describes the pattern of favoritism in your family?

$$
\text { frequency percent }
$$
a. the favorite has always been the same person
b. different children have been favored at different times
c. no one child has been favored 82 $42.1 \%$ TOTAL 
1 to 5, with 1 indicating an extreme problem and 5 indicating no problem, the majority (54\%) viewed favoritism as no problem, with only $29 \%$ rating it as moderate to extreme ( 1 to 3 ) on the scale.

A one-way ANOVA with two levels was done to test the hypothesis that favorites would show higher levels of selfesteem than non-favorites. The independent variable was the two levels of favorite status, and the dependent variable was self-esteem. Subjects were classified as favorites ( $n=$ 65) if they identified themselves as maternal and/or paternal favorites on the Favoritism Status Questions (See Appendix J) and they scored 10 or higher on either the maternal partiality or paternal partiality subscales of the SRQ. Non-favorites $(n=26)$ were subjects who designated other siblings as maternal and paternal favorites on the Favoritism status Questions and scored 8 or lower on either the Maternal or paternal partiality subscales of the SRQ. Results of this analysis were that favorites reported significantly higher levels of self-esteem (mean= 32.6) than non-favorites $(\operatorname{mean}=29.6),(F(1,89)=5.38 *, p<.023)$, (See Table 20). This supported the original prediction that status as a favorite would be associated with higher selfesteem. 
Table 20

One Way ANOVA of Self-Esteem BY Favoritism status

\begin{tabular}{lcccc}
\hline \multicolumn{1}{c}{ Source } & SS & df & MS & F \\
\hline Between Groups & 204.4488 & 1 & 204.4488 & $5.383 *$ \\
Within Groups & 3380.5402 & 89 & 37.9836 & \\
Total & 3584.9890 & 90 & & \\
$\star \mathrm{p}<.05$ & & & & \\
\hline
\end{tabular}

A one-way ANOVA with 3 levels was done to test the hypothesis that favorites and non-favorites would have lower levels of personal authority within the family system than subjects who identified no favoritism in their families, or "neutral" subjects. The independent variable was the three levels of favorite status, and the dependent variable was total PAFS-Q score. Subjects were classified as favorites $(n=65)$ and non-favorites $(n=26)$ using the procedures described above. The neutral group $(n=65)$ consisted of subjects who identified no favoritism on the Favoritism Status Questions and scored between 7-11 on the maternal and paternal partiality subscales of the SRQ.

Results of the ANOVA showed significant mean differences in PAFS-Q scores for favorites, non-favorites, and neutrals $(F(2,153)=17.058 * * *, p<.0001)$ (See Table 
21). Non-favorites had the lowest mean scores (mean= 268.53); favorites had much higher scores (mean= 301.94); and neutrals had the highest scores (mean= 307.83$)$.

Table 21

One Way ANOVA of Total PAFS-Q Scores by Favoritism status

\begin{tabular}{lcccc}
\hline \multicolumn{1}{c}{ Source } & SS & df & MS & F \\
\hline Between Groups & 29762.56 & 2 & 14881.28 & $17.058 * * * *$ \\
Within Groups & 133477.32 & 153 & 872.40 & \\
Total & 163239.88 & 155 & & \\
$* * * * p<.0001$ & & & & \\
\hline
\end{tabular}

Newman Keuls tests of mean PAFS-Q scores for the different levels of favoritism status revealed that nonfavorites had significantly lower levels of personal authority than both favorites and neutrals (See Table 22). In other words, the hypothesis was only partially supported, since the non-favorites had significantly lower mean scores than neutrals, but the favorites' mean scores were not significantly lower than those of the neutrals. 
Table 22

Newman Keuls Test of Mean PAFS-Q Scores By Favoritism status Non-Fav. Fav. Neut. 301.53 307.83

Non-Fav. 268.53

$33.41 *$ $39.30 *$

Fav. 301.94

$-----$

5.89

Neut. 307.83
$q_{\alpha} .05(r, 153)$
2.77
3.31

a $\sqrt{\text { MS error } / \tilde{n}}=4,48$ 12.40 14.82 


\section{DISCUSSION}

The results of this study reveal some important similarities as well as differences between sibling jealousy and other types of jealousy described in the literature. consistent with research on romantic jealousy, this study found sibling jealousy to be highly dependent on situational and relationship factors. Both the people involved in the comparison process and the domain or trait generating the comparison seem to make a difference in the intensity of jealous reactions among siblings.

similar to research on romantic jealousy, this study found that sibling jealousy is first and foremost an emotional reaction. Emotional responses of hurt, anger, and upset are the most potent and interrelated components of sibling jealousy. Findings from the factor analysis of the sibling jealousy measure in this study showed that the items measuring emotional responses had by far the highest loadings on the one primary factor being measured. This same pattern has been found for factor analyses of romantic jealousy measures (Bryson, 1991).

Results of the factor analysis also showed that the cognitive strategy of trying to figure out the reasons behind the situation, and the behavioral response of pulling away or avoiding the persons involved were important components of sibling jealousy. Therefore, like romantic jealousy, sibling jealousy appears to be a complex response 
made up of emotional, cognitive, and behavioral factors (White \& Mullen, 1989).

Situational Factors in Sibling Jealousy

The finding that parent-initiated comparisons produced greater sibling rivalry than sibling-initated comparisons supports the central hypothesis generated by the SEM model that jealousy varies with the situation or type of comparison being made. Based on the SEM model, this study assumed that parental comparisons would heighten jealousy by making the self-evaluation process more salient, especially when parents acted on their comparisons by showing favoritism. Even with the effects of fairness partialled out, parent-initated jealousy was significantly greater than sibling-initiated jealousy.

There may be other reasons why parental involvement in the comparison process seems to make a difference. Recall that jealousy is defined as a complex of thoughts, emotions, and actions resulting when there is a threat to self-esteem or to a relationship (White \& Mullen, 1989). When parents call attention to a sibling's superiority in a given area, both self-esteem and the parental relationship are threatened, increasing the jealous response. In contrast, simple sibling comparisons may threaten self-esteem, but they only carry an implied threat to the parental 
relationship. When parents make the comparison, the threat to the relationship becomes real.

The findings for sibling-initiated comparisons in this study partially support those of other jealousy studies based on the SEM model, showing that individuals are more jealous along domains of higher importance to them (Salovey \& Rodin, 1984; Bers \& Rodin, 1984). The sibling-initiated jealousy vignettes on domains rated as more important by the subjects (i.e., social competence, intellectual achievement, physical attractiveness, maturity, and occupational acheivement) produced significantly greater jealousy than the lower-importance vignettes (i.e. wealth, athletic achievement, and artistic achievement). This implies that siblings make logical discriminations between situations of high and low threat to their self-esteem. When one sibling outperforms another, the comparison is less painful if it is in and area that is not as self-defining.

The parent-initiated comparison process seems more complicated, according the the findings of this study. The original hypothesis was that since parent-initiated comparisons would produce more heightened and global jealousy, there would be no difference between responses on vignettes representing high and low importance domains. This hypothesis was not supported by the findings of this study. Unexpectedly, the lower importance vignettes produced greater parent-initated jealousy than the higher 
importance vignettes. What is the explanation for these counterintuitive results?

One possiblity is that siblings expect parental comparisons on high importance domains (e.g., intelligence, social competence, attractiveness, maturity, occupational achievement), but are more surprised and therefore more reactive to comparisons in lower importance areas (e.g., artistic achievement, athletic achievement, wealth). The latter comparisons stand out as more unusual, and therefore more hurtful.

Another possiblity is that the relevance of the domain is less influential for parent-initated comparisons. Perhaps parental comparisons create more emotional reactivity, making it harder to discriminate between high and low importance situations. An examination of the mean jealousy responses for the different vignettes (See Table 5) reveals that the parallels between the levels of jealousy and the levels of importance for the domains are much clearer for the sibling-initated vignettes than for the parent-initated vignettes. Variables other than the importance of the domain may enter the process for parentinitated comparisons, clouding the process and influencing the pattern of reactions.

An interesting aspect of the findings of this study was the kinds of situations that generated the most sibling rivalry. For both the sibling and parent-initated 
vignettes, the areas producing the greatest jealousy were physical attractiveness, social competence, and athletic achievement. Since physical attractiveness and social competence were rated as domains of high importance for this sample, this probably accounts for the high jealousy in these areas. Developmentally, the college years are a time when peer relationships are of prime importance.

Attractiveness and social skills are characteristics that may strongly influence the development of successful peer relationships. This may be one reason why these domains are more salient and more likely to produce jealousy in this college student sample.

Athletic achievement is a domain that was rated as low in importance, but generated a high amount of jealousy for both parent and sibling-initiated comparisons. This discrepancy is interesting, and may indicate that the participants were less aware of how important their athletic abilities really were to them. Another possiblity is that the competitive nature of athletic achievement automatically engenders more jealousy by heightening the comparison process.

Interestingly, comparisons in occupational achievement produced relatively low jealousy for this sample. This may be because college students have not yet started their careers. If they have not experienced occupational comparisons yet, they may not carry much valence. In 
addition, this is one domain over which they may have some control. If they fall short in this area, they can work harder or change their occupational choice to rectify the situation.

Correlates of Sibling Jealousy

one important purpose of this study was to investigate possible correlates of sibling jealousy, since there has been little research in this area. The findings for this portion of the study underscore the importance of using direct measures for hypothesis testing with individual and relationship variables in jealousy. Although the vignettes were useful for investigating key aspects of situational jealousy, indirect methods were not as useful for examining more personal aspects of the jealous response. Most of the individual and relationship variables in this study did not correlate with jealousy on the vignettes. However, the findings for the direct measures are quite interesting and compelling.

One of the most intriguing findings of this study concerns the relationship between family atmosphere and direct measures of sibling rivalry versus sibling conflict. As might be expected, higher levels of family conflict predicted higher levels of sibling rivalry. In other words, a family atmosphere characterized by more antagonism, unhappiness, and fractured family unity also tended to have 
higher levels of sibling rivalry. However, a more positive, secure, and less conflictual family atmosphere was associated with higher sibling conflict. What might account for these contrasting results?

The answer may lie in the subtle, yet important differences between the concepts of sibling rivalry and sibling conflict. Sibling rivalry as operationalized by the SRQ consists of maternal and paternal partiality subscores. In other words, sibling rivalry on this scale means perceived preferential treatment or favoritism. In essence, the findings of this study show that favoritism toward siblings was associated with a more conflictual family atmosphere. However, higher conflict (i.e., quarreling, antagonism, and competition on the SRQ) was correlated with a less conflictual family atmosphere.

Perhaps the most optimal family atmosphere is one which minimizes favoritism, but allows open conflict among siblings. Preferential treatment of siblings is bound to create an unhappy family environment. However, open conflict between siblings may be productive. It may be healthier for siblings to air their differences than to suppress them.

Viewed from the other angle, families which are highly conflictual may breed greater sibling unity. As Bank \& Kahn (1982) note, when parents are emotionally absent and family 
unity is lacking, siblings may need to minimize their own conflicts and reach out to one another for survival.

Sibling warmth has a more straightforward relationship with rivalry and conflict, according to the findings of this study. Lower sibling warmth, as measured by the prosocial, affection, companionship, similarity, intimacy, and admiration subscales of the SRQ, predicted both higher sibling rivalry and higher sibling conflict. This finding may be an artifact of the factor structure within the subscales of the SRQ. Since sibling rivalry, conflict, and warmth are separate factors within this instrument, it makes sense that they would measure discrete, contrasting entities.

However, these findings do not completely support those of the original PCA done when the SRQ was developed by Furman \& Buhrmester (1985). Similar to this study, the original PCA found an inverse correlation between sibling warmth and sibling rivalry. However, the original PCA found that sibling warmth and sibling conflict were uncorrelated. The authors concluded that mixed feelings toward siblings often coexist, and that sibling warmth and conflict were not polar opposites.

The difference between their findings and those of this study may stem from the age differences in the samples. Furman \& Buhrmester's (1985) sample consisted of fifth and sixth grade children. As these researchers note, siblings 
who have more frequent and intense interactions (such as younger siblings still living together) may be likely to have both more positive and more negative interactions. As siblings go off to college and see each other less often, they may tend to shift toward either greater closeness or greater conflict. The contrast between Furman \& Buhrmester's findings and those of this study underscores the importance of investigating developmental aspects of sibling relationships.

Based on the SEM model, smaller age differences between siblings were expected to produce more jealousy by increasing sibling closeness and heightening the comparison process. However, this study found no relationship between the number of years to closest sibling and either direct or indirect measures of jealousy. Whereas Furman \& Buhrmester (1985) found in younger children that closeness in age correlated with greater sibling conflict and less sibling rivalry, no such relationships were found in this study. It may be that closeness in age has less impact on jealousy and conflict as siblings grow older.

Whereas self-esteem has been shown to correlate strongly with romantic jealousy, this variable showed no significant correlation with either direct or indirect measures of sibling jealousy in this study. This was surprising because one of the defining features of jealousy is a threat to self-esteem. Apparently, low self-esteem 
creates no particular vulnerability to sibling jealousy. other individual-level variables yet to be identified may play a more important role.

Personal Authority in the Family system and sibling conflict An exciting and promising finding of this study is the strong relationship between key dimensions of personal authority in the family system and sibling rivalry and conflict. The findings for this variable may help to clarify developmental aspects of these phenomena.

Lower overall personal authority within the family system was correlated with higher sibling conflict in this study. Perhaps sustained conflict with siblings is a sign of difficulty letting go of old role relationships and moving on to a more mature, differentiated position within the family system. A certain amount of conflict with siblings is healthy, but too much for too long may impede healthy development. At some point, siblings need to accept each other's differences and learn to relate without continuous struggle and competition.

Two other sub-dimensions of personal authority were significantly related to direct measures of sibling conflict in this study. First, greater intergenerational intimidation was associated with higher sibling conflict. Intergenerational intimidation refers to the need to live up to and change one's behavior and goals to correspond with 
parental expectations and demands, and the inability to be assertive with one's parents (Bray \& Harvey, 1987). Perhaps siblings who feel pressured and unable to assert themselves with parents channel their frustrations toward their siblings.

Another possiblity is that a family environment in which parental demands are strong engenders more competition and conflict among siblings. If this is so, it points toward another explanation for the finding that a more positive family atmosphere correlates with lower sibling conflict. Perhaps a less confictual family atmosphere is a smokescreen for a more authoritarian system in which parents are never challenged. Siblings who are more motivated by parental approval and expectations may have a higher need for social desirability and therefore rate their families as more harmonious and unified.

The second variable which predicted higher sibling conflict was higher triangulation. It seems logical that triangles involving inappropriate coalitions between parents and siblings would breed resentment and antagonism. Children who are more closely involved with a parent may also be the object of envy, a problem which exacerbates sibling conflict. Indeed, as will be discussed further below, triangulation was not only a predictor of sibling conflict, but also a strong predictor of every measure of sibling jealousy. 
Personal Authority in the Family system and sibling Jealousy

The total PAFS-Q score which combines all dimensions of the personal authority concept did not correlate significantly with direct and indirect measures of jealousy in this study. This may be because there appears to be a complex relationship between key dimensions of the personal authority measure and jealousy. Certain subscales of the PAFS-Q correlated strongly with sibling jealousy, but some of these correlations were negative and some positive. $A$ closer look at the results reveals some noteworthy patterns. For example, there was an interesting twist in the findings for one dimension of the personal authority measure. Although high scores on most of the PAFS-Q subscales correlated with lower levels of jealousy, low scores (i.e., lower levels of progress) on the intergenerational intimacy subscale produced lower levels of jealousy on all of the direct and indirect measures.

Note that the concept of personal authority within the family system places value on a combination of high individuation from the family and high intimacy with parents. The goal is to psychologically separate from parents, yet still remain close. According to the findings of this study, some aspects of greater personal authority were associated with lower sibling jealousy, but lower intimacy with parents also correlated with lower jealousy. In this sense, low jealousy may not be such a positive sign. 
If less jealousy stems from less involvement in the relationship, it may come at a high price. Perhaps siblings who are less jealous simply do not care as much about their relationships with parents because they do not feel as close. As other researchers have observed, jealousy may be a healthy response when it signals a threat to a valued relationship (Bringle \& Buunk, 1986).

Lower levels of triangulation between parents were found to predict lower jealousy on both direct and indirect measures in this study. This dimension of personal authority was a very strong predictor. Lower levels of triangulation were associated with lower sibling-initiated, parent-initiated, and global jealousy on the vignettes and with lower sibling rivalry on the SRQ. Regardless of the type of comparison situation, being less triangulated with parents reduced the intensity of the jealous response.

A number of factors may account for the strong relationship between triangulation and jealousy. When a child is pulled into an overly close relationship with one parent and becomes alienated from the other, it makes sense that the situation is ripe for jealousy. The strong bond with the close parent would make the child more vulnerable to threats to this relationship. Parents who cling to a child as a buffer in the marital relationship may actually end up favoring the child in exchange for support and nurturance. Children who are triangulated into 
inappropriate coalitions with a parent usually share secrets with the parent and experience the relationship as special and unique. They may see parental comparisons favoring other siblings as acts of betrayal. Hidden fears that the rival could win the special place that the triangulated sibling now occupies may intensify the jealous reaction.

The finding that triangulation was a strong predictor of jealousy is interesting in light of the fact that jealousy is often characterized as a triangle. In the case of sibling jealousy and favoritism, there may be two triangles: 1) the child aligned with one parent and alienated against the other, and 2) the sibling who is left out of the special relationship between the favored child and parent.

It would be interesting to investigate the prevalence in which the alienated child bonds with the alienated parent. Indeed, schachter (1985) found that this type of pattern often evolves in families with "devil versus angel" sibling roles. She calls this "split-parent identification", a phenomenon in which each child identifies with a different parent in a special type of "quadrangle". Further studies investigating this phenomenon and the role of triangulation in sibling jealousy and conflict seem warranted in view of the strong correlations found in this study.

There were a few dimensions of personal authority that correlated only with either direct or indirect jealousy 
measures in this study. These results suggest that the direct and the indirect measures each tapped slightly different dimensions of the jealousy concept.

Higher peer intimacy and lower intergenerational individuation were correlated with higher sibling rivalry, only on the direct measure. Recall that the direct measure of sibling rivalry from the SRQ focuses on differential treatment or favoritism. Perhaps the perceived experience of favoritism in one's own family provokes movement toward greater intimacy with peers in reaction to feelings of rejection by parents. Previous results indicated that favoritism was associated with higher sibling conflict. Perhaps the strain between siblings creates a need to rely more on friendships outside the family.

The finding that lower intergenerational individuation is associated with higher sibling rivalry on the direct measures supports the notion that perceptions of favoritism in one's own family may either create or reflect more difficulty separating from the family in a healthy way. This finding, combined with the finding that higher peer intimacy was correlated with higher sibling rivalry, suggests that a possible escape into peer relationships may only be a cover for unresolved feelings about parental relationships. Lower individuation means less autonomy and more emotional reactivity to parents. Children who perceive favoritism in their families may give the appearance of 
separating from home by getting more involved with peers, but they may still be reacting to their parents' expectations and having difficulty letting go of their need for parental approval.

Higher scores on the personal authority subscale of the PAFS-Q were associated with lower global and parentinitiated jealousy on the vignettes, but not correlated with direct measures of sibling rivalry. Why would this particular dimension only correlate with the indirect measures of jealousy? The personal authority subscale focuses on interactional patterns and the child's comfort with discussing sensitive topics with parents. Perhaps siblings with higher scores on this dimension react less to indirect parental comparisons because they have confidence that they could interact with their own parents in a way that would mitigate against the effects of comparisons. When examining hypothetical situations, they may have more faith that they could discuss the problem and reach an adequate solution. However when it comes to questions about actual differential treatment in their own families, there is no correlation between these two variables because interactional skills cannot change what has already taken place. 
Family Constellation Variables

Intactness of the family structure was the only family constellation variable that predicted sibling rivalry in this study. Coming from a non-intact family (i.e., one in which the parents were separated, divorced, or remarried) was associated with higher levels of sibling rivalry in the subjects' own families. These results support those of Robey, Cohen, \& Epstein (1988) who found that children from divorced families were more sensitive to differential attention from their parents. The loss of a parent may create greater vulnerability to the comparison process. If jealous reactions partially stem from threats to a valued relationship, the threat may be more salient for children who have already experienced the loss of a parent.

Parental separation sometimes causes siblings to take sides or form alliances with one parent against the other (Combrinck- Graham, 1988). We have already seen that this type of triangulation process is associated with differential treatment or favoritism. This process may be magnified in remarried or blended families where conflicting loyalties can create strong bonds with the natural parent and alienation from the step-parent (Rosenberg, 1988). Children from blended families may be particularly sensitive to favoritism between step-parents and their own natural children. 
Being higher in the birth order (i.e. older versus younger) and having same sex siblings were the family constellation variables which predicted higher levels of sibling conflict in this study. Clinicians have long noted that oldest children may have a greater adjustment to the birth of a sibling because they have been the only child and the parents' sole focus of attention. For this reason, there is often conflict between first and second children (Hoopes \& Harper, 1987). In contrast, younger children are more often the objects of caretaking by older children ( Toman, 1988).

The finding that having same sex siblings is associated with higher sibling conflict is consistent with the SEM model, since similarity may be greater among same-sex siblings, heightening the comparison process. Other researchers have also found greater conflict among same sex siblings (Toman, 1988). When siblings are all the same gender they may need to struggle more to find their own place within the family system. Schachter (1985) found that greater "deidentification" or development of contrasting traits and roles, takes place among same sex siblings. She notes that clinical problems often develop when siblings find themselves in fixed "devil versus angel" roles which are hard to alter. The pressure to live up to the perfect child role or the image of oneself as the black sheep may have obvious adverse effects on sibling development. These 
types of polarities are bound to create conflict between siblings.

None of the family constellation variables correlated with indirect measures of jealousy from the vignettes in this study. This pattern of correlations for direct versus indirect measures may point toward one reason for the inconsistent findings for family constellation variables in other jealousy studies. Some of the other studies which have found that family constellation variables had no predictive value have used indirect measures of jealousy (Bers \& Rodin, 1984). It may be particularly important to use direct measures of jealousy when studying individuallevel variables such as birth order, sex of siblings, and intactness of family structure.

Favoritism

The finding that $65 \%$ of subjects in this sample identified favorites in their families was particularly striking. Apparently, in spite of taboos against acknowledging it, favoritism does exist, at least in the eyes of siblings. Interestingly, a sizable portion of the sample (17\%) identified themselves as the favorite. These findings reflect a willingness of siblings to examine how they themselves may be receiving preferential treatment. Reports of favoritism were not just externalizing 
accusations against others; subjects were able to see themselves as potential objects of envy by their siblings. on the other hand, an even greater proportion of the sample (21\%) saw themselves as both maternal and paternal nonfavorites. If their perceptions are valid, there may be important implications for their feelings about themselves and their families.

As predicted, the favorites in this study reported significantly higher levels of self-esteem than the nonfavorites. Apparently, the perception of oneself as a favorite enhances self-esteem. Another possibility is that self-esteem affects the child's perceptions of favoritism by parents. Children with higher self-esteem may be more tuned into their parents' good will and positive feelings, while those with lower self-esteem may be more sensitive to their parents' preferential treatment of other siblings. A small slight may be particularly painful for children with low self-esteem.

As predicted, there were significant differences in levels of personal authority within the family system for favorites, non-favorites, and neutrals. Non-favorites had significantly lower personal authority than both favorites and neutrals. Perhaps non-favorites have unresolved anxieties about parental approval which prevent them from moving on to more autonomous, mature relationships with their families. One way of describing personal authority is 
that it represents the attainment of "psychosocial peerhood" with one's parents (Bray \& Harvey, 1987). How can a child feel fully accepted by a parent who is perceived as favoring another child?

Although favorites had slightly lower mean levels of personal authority than subjects who perceived no favoritism in their families, the differences were not statistically significant, contrary to predictions. It does appear that a lack of perceived favoritism is most conducive to the development of personal authority, but if favoritism exists, the effects on the favorites are not signficant enough to impede their development. The special bond between favorites and their parents seems more easily transformed into a healthy adult relationship than the alienation or strained relationship experienced by the non-favorite.

Studies show that young adults in clinical psychiatric settings have lower levels of personal authority than nonclinical samples (Bray \& Harvey, 1987). These data, combined with the findings of this study, point toward the possibility that non-favorites may be at higher risk for the development of psychopathology. This possiblity is an important consideration for future studies on the effects of favoritism on individual development. 
Conclusion

In conclusion, the results of this study support other recent advances in jealousy research emphasizing the importance of interrelationships between situational, relationship, and individual variables. A variety of factors come together to influence the jealous response. Although sibling jealousy is similar to romantic jealousy in several ways, there are enough differences to warrant separate studies of the phenomena.

Major limitations of this study include the use of indirect projective techniques for some of the hypothesis testing, and the restrictive nature of the college student sample. Future studies using direct measures of sibling jealousy in families, and sampling from different age groups may shed more light on the process. Results of this study suggest that sibling jealousy does not end when children leave home. It would be interesting to explore how potent this issue remains for adults at other phases of development.

A final limitation of this study that bears repetition is that the reports of favoritism were based on sibling perceptions alone, without verification from other family members. Total family studies may provide more valid reports, helping to clarifiy what seems to be a complex process. 
Most families probably maintain an intricate system of checks and balances among siblings over time. As one participant in this study commented "Whoever needs the attention, gets it". Another summarized his impressions by saying, "In the end the favoritism experienced works out. In my opinion, it is natural to a certain extent. Both parents may have different interests/opinions which a child of theirs shares. This would make them close. I would not call that favoritism." 


\section{APPENDIX A}

\section{Sibling-Initiated Jealousy Vignettes}

(Occup. Achiev.)

1) Bob and his brother make the same amount of money. Bob is a union laborer, and his brother runs his own company.

(Social Competence) 2) John's brother is always "the life of the party". John often finds himself alone in a corner at parties, struggling to connect with other people.

(Maturity)

3) Lisa and her sister are in their thirties. The sister is established in her career. Linda still has not figured out what she wants to do with her life. Her relationships come and go, and she can't seem to settle down for any length of time.

(Phys. Attr.)

4) Jane's sister has always been very attractive. Jane tries to make the best of her appearance by staying thin and dressing nicely, but she just is not very attractive.

(Intelligence)

5) Mike's brother is a straight A student who scored in the genius range in I.Q.. Mike is of average intelligence and gets B's and C's in school.

(Athletic Achiev.)

6) Tom's brother is a superb athlete. Tom has never been very wellcoordinated or good at sports.

(Wealth- Achiev.)

7) Since she won the lottery, Lisa's sister has a $\$ 100,000$ per year income. Lisa has a $\$ 30,000$ per year income.

(Artistic Achiev.)

8) Nancy's sister is a successful artist. Nancy has never been very talented in this area. 


\section{APPENDIX B}

Parent-Initiated Jealousy vignettes

(Occup. Achiev.)

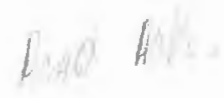

(Social Competence)

(Maturity)

(Phys. Attr.)

(Intelligence)

(Athletic Achiev.)

(Wealth-Achiev.)

(Artistic Achiev.)
1) A man owns a large restaurant business with 200 employees. He appoints one son president and manager of the company, while the other son Joe is one of several chefs.

2) A father is having a conversation with his son, Larry. He drops the conversation mid-sentence when his other son comes in because the other son is more enjoyable to talk with.

3) A mother enjoys talking with her married daughter about marriage, children, and other topics. She avoids talking with her other daughter, Tina who has not married and seems to be drifting.

4) On his des, a father displays a very large picture of his attractive daughter and a small snapshot of his unattractive daughter, carol.

5) A mother brags about how smart her son is. She never mentions the other son Bill who is less intelligent.

6) A man with an athletic son is a major fan who attends all of his son's games. He spends very little time with his other son, Jim who is not athletic.

7) A mother has two daughters who make about the same amount of money. The mother leaves her home and most of her money to one daughter. She leaves a small sum of money to the other daughter, Mary.

8) A mother attends her daughter's art shows and proudly displays her paintings in her home. She shows little interest in her other daughter, Debbie's less successful artwork. 


\section{Appendix c}

Response Format: sibling-Initiated Vignettes

Bob and his brother make the same amount of money. Bob is a union laborer, and his brother runs his own company.

1. How upset do you think Bob would be about this situation?

$\begin{array}{lllll}1 & 2 & 3 & 5 \\ \text { very upset } & & \text { moderately } & & \text { not upset }\end{array}$

2. How hurt do you think Bob would be about this situation?

$\begin{array}{lllll}1 & 2 & 3 & 5 & 5 \\ \text { very hurt } & & \text { moderately } & & \text { not hurt }\end{array}$

3. How angry do you think Bob would be about this situation? $\begin{array}{lllll}1 & 2 & 3 & 5 \\ \text { very angry } & & \text { moderately } & 4 & \text { not angry }\end{array}$

4. How likely would Bob be to try to figure out the reasons behind the situation?
very $\stackrel{1}{l}$ ikely
2
moderately
4
5
not likely

5. How likely would Bob be to try to tell himself it doesn't matter?
very likely
2
$\stackrel{3}{\text { moderately }}$
4
5
not likely

6. How likely would Bob be to avoid or pull away from his brother?
very $\stackrel{1}{l}$ ikely
2
$\stackrel{3}{\text { moderately }}$
4
5
not likely

7. How likely would Bob be to talk to his brother about the situation?
very $\stackrel{1}{\text { likely }}$
2
3
moderately
4
5
not likely

8. How fair is this situation?
1
very fair
2
3
moderately
4
5
not fair 


\section{APPENDIX D}

\section{Response Format: Parent-Intitiated Vignettes}

A man owns a large restaurant business with 200 employees. He appoints one son president and manager of the company, while the other son Joe is one of several chefs.

1. How upset do you think Joe would be about this situation? 1 very upset

2

moderately
4 not upset

2. How hurt do you think Joe would be about this situation?

1

very hurt
2

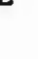

4

moderately
5

not hurt

3. How angry do you think Joe would be about this situation?
very angry
2
3
moderately
4
5
not angry

4. How likely do you think Joe would be to try to figure out the reasons behind the situation?
1
2
3
4
5
very likely
moderately
not likely

5. How likely do you think Joe would be to tell himself it doesn't matter?
1
2
3
4
5
very likely
moderately
not likely

6. How likely do you think Joe would be to avoid or pull away from his father?

very likely 2 moderately $4 \quad$ not likely

7. How likely do you think Joe would be to talk to his father about the situation?

very $\stackrel{1}{l i k e l y} \quad 2 \quad \begin{aligned} & 3 \\ & \text { moderately }\end{aligned}$

8. How fair is this situation?
very fair
2
3
moderately 


\section{Appendix E}

Items for Assessing Jealousy Domains

Please describe yourself currently on the following dimensions by circling the appropriate rating:

85. How important is your athletic ability to you?
1
2
3
somewhat
important
important
4
5
very
important

86. How important is your intellectual ability to you?
1
not
2
3
4
5
very
important
somewhat important important

87. How important is your level of maturity to you?
1
2
3
4
5
not
important
somewhat important

88. How important is your physical appearance to you?
1 2
3
4
5
not
somewhat
important
important
very
important

89. How important is your level of wealth to you?
1
2
3
4
not
somewhat
important
important
5
very important

90. How important is your ability to socialize and interact well with others to you?
1
2
3
not
somewhat
important important
4
5
very important

91. How important is having a highly respected career to you?

1

not

important
2

3
somewhat
important

important
4 5

very important 
92. How important is your artistic ability to you?

1

not

important
2

3

somewhat

important
4 5

very important 


\section{Appendix $\mathbf{F}$}

\section{Rosenberg self-Esteem scale}

Please describe yourself currently on the following dimensions by circling the approriate rating:

129. I feel that I'm a person of worth, at least on an equal plane with others.

1

strongly

agree
2

34

strongly

disagree

130. I feel that I have a number of good qualities. $1 \quad 2 \quad 3 \quad 4$ strongly

strongly agree

disagree

131. All in all, I am inclined to feel that I am a failure. 1 strongly

3 strongly agree disagree

132. I am able to do things as well as most other people. $1 \quad 2 \quad 3 \quad 4$ strongly

strongly agree disagree

133. I feel I do not have much to be proud of.

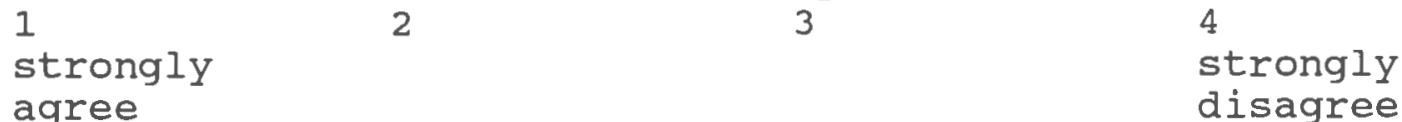

134. I take a positive attitude toward myself.

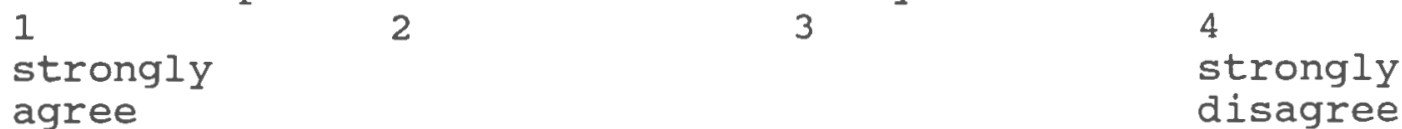

135. On the whole, I am satisfied with myself. $1 \quad 2 \quad 3 \quad 4$ strongly agree strongly disagree

136. I wish I could have more respect for myself. 1 2 3 strongly agree

4 strongly disagree

137. I certainly feel useless at times. 123 strongly agree

344 strongly disagree 
138. At times I think I am no good at all.

1

strongly

agree
2

3 strongly

disagree 


\section{Appendix G}

\section{Famlly Atmosphere Questionnaire (Form B)}

Please describe your family currently on the following dimensions by circling the appropriate rating.

1. Sense of family unity:

$\begin{gathered}\text { We have a } \\ \text { closely united } \\ \text { family. }\end{gathered}$
$\begin{gathered}1 \\ \text { family }\end{gathered}$

2. Sense of security:

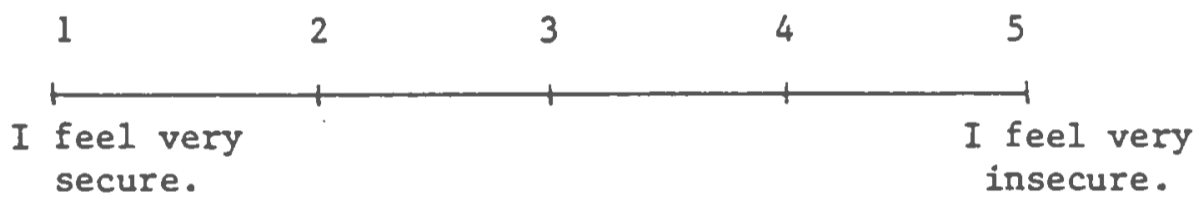

3. General happiness or unhappiness:

$\begin{gathered}\text { We have a } \\ \text { very happy } \\ \text { family. }\end{gathered}$
ramily

4. Relationship between parents:

$\begin{aligned} & \text { My mother and father } \\ & \text { have no areas of conflict } \\ & \text { that I am aware of. }\end{aligned}$
$\begin{gathered}\text { My mother and father } \\ \text { are in constant open } \\ \text { conflict. }\end{gathered}$

5. Relationship between my parents and me:

$\begin{aligned} & \text { My parents and I } \\ & \text { have no areas of conflict }\end{aligned}$
$\begin{gathered}\text { that I am aware of. } \\ \text { that }\end{gathered}$




\section{Appendix H}

Favoritism status Questions

Please mark your answers directly on the page:

1. Looking back over the past five years, who has been your mother's favorite? (Check one.)

older brother

older sister

younger brother

younger sister

you

noone in particular

2. What is it that your mother likes about the favorite? (Check all that apply.)

special talent

occupational acheivement

intellectual ability

physical appearance

close relationship

social charm/personality

need for attention due to sickness

or other weakness

they have a lot in common

other (please list)

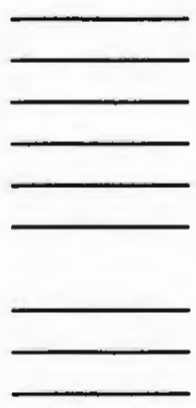

3. Looking back over the past five years, who has been your father's favorite? (Check one.)

older brother

older sister

younger brother

younger sister

you

noone in particular

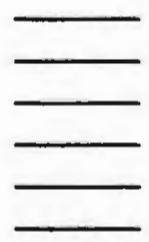

4. What is it that your father likes about the favorite? (Check all that apply.)

special talent

occupational acheivement

intellectual ability

physical appearance

close relationship

social charm/personality

need for special attention

or other weakness

they have a lot in common

other (please list) 
5. How much of a problem has favoritism been in your family? (Circle below.)
a
b
c
d
e
extreme
sometimes
problem
problem
not
problem

6. Which of the following best describes the pattern of favoritism in your family? (Check one.)

the favorite has always been the same person

different children have been favored at

different times

no one child has been favored

Any other comments about favoritism in your family?

Thank you very much! 


\section{Appendix I}

\section{Informed Consent Form}

I understand that:

1. I have been asked to participate in Ms. Catherine Deering's dissertation survey designed to learn about views of family relationships among college students like myself. My time and effort in answering a number of questions is essential to the success of the survey.

2. I will be asked to complete several questionnaires. These questions should take approximately 1 1/2 hours to complete.

3. All information gathered in this survey will be kept strictly confidential. My name will not be on the questionnaires. All answers will be tabulated, analyzed, and reported anonymously as part of a large group analysis of data.

4. A possible risk of this survey is that it may create some mild anxiety if it causes me to think about potentially negative aspects of family relationships.

5. A possible benefit of this survey is that it may increase psychology's understanding of various aspects of family relationships and thereby help others. However, the survey is not designed to be of direct benefit to me.

6. I am a volunteer and may withdraw from the survey at any time. Whatever I decide will in no way affect my grade or status as a student. If I wish to quit, I simply inform Ms. Deering of my decision.

7. If I have any questions about the survey, I may ask Ms. Deering when I have finished completing the forms, or I may contact her later at (404) 892-5889.

8. The information I give is very important and therefore my honest answers to the questions are essential.

I have read and understood the above statements concerning my voluntary participation in this survey on views of family relationships, and I hereby consent to participate. 


\section{Appendix $J$}

\section{Demographic and Family Information Items}

1. Age

2. Sex

3. Race

4. College major

5. College major, occupation, or career goal of sibling closest to you in age

6. Number of natural children in your family

7. Number of step or adopted children in your family

Please use the computer form to answer the following questions:

1. Which of the following best describes your family composition?
a) parents living together
b) parents divorced
c) parents separated
d) one parent deceased
e) both parents deceased

2. Which of the following positions do you occupy in your family?
a) oldest child
b) middle child
c) youngest child
d) only child

3. How many brothers did you grow up with?
a) 0
b) 1
c) 2
d) 3
e) 4 or more 
4. How many sisters did you grow up with?
a) 0
b) 1
c) 2
d) 3
e) 4 or more

5. How many years apart is the sibling closest to you in age?
a) 1-2 years older
b) 1-2 years younger
c) 3-4 years older
d) 3-4 years younger
e) 5 or more years older or younger

6 . What is your mother's highest level of education?
a) grade school
b) high school
c) training beyond high school
d) college graduate
e) post-graduate work

7. What is your father's highest level of education?
a) grade school
b) high school graduate
c) training beyond high school
d) college graduate
e) post-graduate work

8. What has been your parents' general level of employment for the past five years?
a) single parent family
b) mother and father both work outside the home
c) father works outside the home; mother does not
d) mother works outside the home; father does not
e) mother and father both unemployed or retired 


\section{BIBLIOGRAPHY}

Adams, B.N., (1968). Kinship in an urban setting. Chicago: Markham .

Amstutz, D. (1982). Androgyny and jealousy. Unpublished doctoral dissertation.

Bank, S. (1987). Favoritism. Journal of Children in Contemporty society, 19, (3-4), 77-89.

Bank, S. \& Kahn, M.D. (1982). The sibling bond. NY: Basic Books .

Bers, S.A. \& Rodin, J. (1984). Social comparison jealousy: A developmental and motivational study. Journal of Personality and Social Psychology, . 47:4,766-779.

Bray, J.H. \& Harvey, D.M. (1987). Intimacy and individuation in young adults: Development of the college student version of the Personal Authority in the Family system Questionnaire. Unpublished manuscript. 
Bray, J.H., Williamson, D.S., \& Malone, P.E. (1984). Personal authority within the family system: Development of a questionnaire to measure personal authority in intergenerational family processes. Journal of Marital and Family Therapy, 10, 167-178.

Bringle, R.G. \& Buunk, B. (1986). Examining the causes and consequences of jealousy: some recent findings and issues. In R. Gilmour \& S. Duck (Eds.), The emerging field of personal relationships. Hillsdale, NJ: Erlbaum, $225-240$

Bringle, R.G. \& Gray, K. (1986). Jealousy and the third person in the love triangle. Unpublished manuscript. Indiana University at Indianapolis.

Bringle, R.G. (1981). Conceptualizing jealousy as a disposition. Alternative Lifestyles, $\underline{4}, 274-290$.

Bringle, R.G. \& Williams, L.J. (1979). Parental-offspring similarity on jealousy and related dimensions. Motivation and Emotion, 3, 265-286.

Bryson, J.B. (1991) . Modes of response to jealousy-evoking situations. In P. Salovey (Ed.). The psychology of jealousy and envy. NY: Guilford Press, 178-205. 
Buunk, B. (1982). Strategies of jealousy: styles of coping with extramarital involvement of the spouse. Family Relations, 31, 13-18.

Cialdini, R.B., Borden, R.J., Thorne, A., Walker, M.R., Freeman, S. \& Sloan, L.R. (1976). Basking in reflected glory: Three (football) field studies. Journal of Personality and Social Psychology. 39, 406-415.

Cicirelli, V.G. (1982). Sibling influence throughout the lifespan. In M.E. Lamb \& B. Sutton-Smith (Eds.) Sibling relationships: Their nature and significance throughout the lifespan. Hillsdale, NJ: Lawrence Erlbaum Associates.

Clanton, G. and Kosins, D.J. (1991). Developmental correlates of jealousy. In P. Salovey (Ed.). The psychology of jealousy and envy. NY: Guilford Press, 132-144.

Combrinck-Graham, L. (1988). When parents separate or divorce: The sibling system. In M.D. Kahn \& K.D. Lewis (Eds.) Siblings in therapy: Lifespan and clinical issues. NY: w.w. Norton, 190-208.

Daniels, D. \& Plomin, R. (1985). Differential experiences of siblings in the same family. Developmental Psychology 21, 5, 747-760. 
Furman, W. (1990). Personal communication, Department of Psychology, University of Denver, Colorado.

Furman, W. and Buhrmester, D. (1985). Children's perceptions of qualities of sibling relationships. Child Development, $56,448-461$.

Gold, D.T. (1989). Generational solidarity: Conceptual antecedents and consequences. American Behavioral Scientist, 33, 1, 19-32.

Hansen, G.L. (1991). Jealousy: Its conceptualization, measurement, and integration with family stress theory. In P. Salovey (Ed.) The psychology of jealousy and envy. NY: Guilford Press, 211-228.

Harris, I.D. \& Howard, K.I. (1983). Correlates of perceived favoritism. The Journal of Genetic Psychology, 146, 1,4556 .

Hazan, C. \& Shaver, P. (1987). Romantic love conceptualized as an attachment process. Journal of Personality and Social Psychology, 52, 511-524.

Hoopes, M.M. \& Harper, J.M. (1987). Birth order roles \& Sibling patterns in family therapy. Rockville, MD: Aspen Publications. 
Hupka, R.B. \& Eshett, C. (1988). Cognitive organization of emotion: Differences between labels and descriptions of emotion in jealousy situations. Perceptual and Motor Skills, $6,935-949$.

Jaremko, M.E. \& Lindsey, R. (1979). Stress coping abilities of individuals of high and low jealousy. Psychological Reports, 44 , 547-553.

Kinniard, K.L. \& Gerrard, M. (1986). Premarital sexual behavior and attitudes toward marriage and divorce among young women as a function of their mothers' marital status. Journal of Marriage and the Family, 48, 757-765.

Koch, H.L. (1956). Some emotional attitudes of the young child in relation to characteristics of his sibling. Child Development, 27,27, 393-426.

Lott, A. (1990). Personal communication, Department of Psychology, University of Rhode Island.

Mchale, S.M., Sloan,J. \& Simeonsson, R.J. (1986). Sibling relationships of children with autistic, mentally retarded, and non-hhcapped brothers and sisters. Journal of Autism and Pervasive Developmental Disorders, $\underline{16}, 4,399-413$. 
Robey, K.L., Cohen, B.D., Epstein, Y.M. (1988). The child's response to affection given to someone else: Effects of parental divorce, sex of child, and sibling position. Journal of Clinical Child Psychology, 17, 1, 2-7.

Rosenberg, E. (1988). Stepsiblings in therapy. In M.D. Kahn \& K.G. Lewis (Eds.) Siblings in therapy: Lifespan and Clinical issues. NY: W.W. Norton, 209-227.

Rosenberg, M. (1965). Society and the adolescent self-image. Princeton: Princeton University Press.

Ross, H.G. \& Milgram, J.I. (1982). Important variables in adult sibling relationships: A qualitative study. In M.E. Lamb \& B. Sutton-Smith, (Eds.). Sibling relationships: Their nature and significance across the lifespan. Hillsdale, NJ: Lawrence Erlbaum Associates.

Salovey, P. \& Rothman, A. (1991). Envy and jealousy: Self and society. In P. Salovey (Ed.). The psychology of jealousy and envy. NY: Guilford Press, 271-284.

Salovey, P. \& Rodin, J. (1984). Some antecedents and consequences of social comparison jealousy. Journal of $v$ Personality and Social Psychology, 47, 4, 780-792. 
Savin-Williams, R.C. \& Small, S.A. (1986). The timing of puberty and its relationship to adolescent and parent perceptions of family interactions. Developmental, Psychology, 22, 343-347.

Schachter, F.F. (1985). Sibling deidentification in the clinic: Devil vs. angel. Family Process, 24,415-427.

Schachter, F.F., Shore, E., Feldman-Rotman, S., Marquis, R.E., \& Campbell, S. (1976). Sibling deidentification. Developmental Psychology, 12, 418-427.

Shoeck, H. (1966) - Envy: A theory of social behavior. NY: Harcourt, Brace, \& World, Inc.

Small, S.A. (1988). Parental self-esteem and its relationship to childrearing practices, parent-adolescent interaction and adolescent behavior. Journal of Marriage and the, 50, 1063-1072.

Stotland, E., Sherman, S.E., \& Shaver, K.G. (1971). Empathy and birth order. Lincoln: University of Nebraska Press.

Tesser, A. \& Collins, J.E. (1988). Emotion in social reflection and comparison situations: Intuitive, systematic, and exploratory approaches. Journal of Personality and Social Psychology, 55, 695-709. 
Tesser, A., Millar, M., \& Moore, J. (1988). Some affective consequences of social comparison and reflection processes: The pain and pleasure of being close. Journal of Personality and Social Psychology, 54, 49-61.

Tesser, A. (1980). Self-esteem maintenance and family dynamics. Journal of Personality and Social Psychology, $\underline{39}, 1,77-91$.

Tesser, A. \& Campbell, J. (1980). Self-definition: The impact of relative performance and similarity of others. Social Psychology Quarterly, 43, 341-347.

Toman, w. (1988). Basics of family structure and sibling position. In M.D. Kahn \& K.G. Lewis, (1988). Siblings in therapy: Lifespan and clinical issues. NY: W.W. Norton, 46-65.

Toman, W. (1976). Family constellation. NY: Springer.

White, G.L. \& Mullen, P.E. (1989). Jealousy. NY: Guilford Press.

White, G.L. (1981). Relative involvement, inadequacy, and Jealousy: A test of a causal model. Alternative Lifestyles, _4, 3,291-309. 
White, G.L. (1980). Inducing jealousy: A power perspective. Personality and Social Psychology Bulletin, 6,2 , $222-227$.

Wylie, C. (1989). Measures of self-concept. Lincoln: University of Nebraska Press. 